\title{
Soot modeling in Turbulent Diffusion Flames: Review and Prospects
}

\author{
Sebastian Valencia, Sebastián Ruiz, Javier Manrique, Cesar Celis ${ }^{\dagger}$
}

Mechanical Engineering Section, Pontificia Universidad Católica del Perú Av. Universitaria 1801, San Miguel, Lima 32, Lima, Peru

\author{
Luís Fernando Figueira da Silva \\ Department of Mechanical Engineering, Pontifícia Universidade Católica do Rio de Janeiro \\ Rua Marquês de São Vicente 225, Rio de Janeiro, RJ 22453-900, Brazil
}

† Corresponding author - Tel.: +51 $16262000 / 4870$

E-mail address: ccelis@pucp.edu.pe (C. CELIS) 


\section{Abstract}

This work reviews the state-of-the-art of the main soot modeling approaches used in turbulent diffusion flames. Accordingly, after a short introduction about the subject addressed here, the main soot formation mechanisms are described next. This description provides the basis for the discussions about the different soot modeling techniques employed nowadays for soot predictions. Since combustion and radiation models have a significant impact on soot predictions, as a consequence of the strong coupling between chemistry, turbulence and soot formation, a general overview about these models is also provided. For the sake of clarity, the main soot formation models reviewed in this work are classified as semi-empirical soot precursor models and detailed ones. Both advantages and disadvantages of the referred soot modeling approaches are properly discussed. In the last part of this review, comparative results obtained using some of the main soot models currently available are presented along with a discussion about the prospects for soot modeling in turbulent flames. Finally, some conclusions and references are provided. Overall, based on the literature reviewed, it is concluded that there is yet a long path to be followed before understanding first and having then a soot model able to properly describe the formation of this critical pollutant for a variety of situations of industrial interest.

Keywords: Soot modeling, turbulent diffusion flames, pollutant formation, computational fluid dynamics. 


\section{Nomenclature}

Variables

\begin{tabular}{|c|c|}
\hline$\dot{Q}_{s, i}$ & Production rate of soot mass fraction \\
\hline$\dot{q}_{s, i}$ & Soot volume fraction density \\
\hline$f_{v}$ & Soot volume fraction \\
\hline$C_{a}$ & Van der Waals enhancement factor \\
\hline$C_{i}$ & Cunningham slip correction factor \\
\hline$C_{\text {oxid }}$ & Empirical rate scaling factor for oxidation \\
\hline$C_{w, 1}$ & Empirical rate scaling factor for oxidation by $\mathrm{OH}$ \\
\hline$C_{w, 2}$ & Empirical rate scaling factor for oxidation by $\mathrm{O}_{2}$ \\
\hline$C_{\alpha}$ & Empirical rate scaling factor for nucleation \\
\hline$C_{\beta}$ & Empirical rate scaling factor for coagulation \\
\hline$C_{\gamma}$ & Empirical rate scaling factor for surface growth \\
\hline$D_{f}$ & Fractal characteristic dimension \\
\hline$L_{k}$ & Lagrange logarithmic interpolation function. \\
\hline$M_{C}$ & Molar mass of carbon \\
\hline$M_{p}$ & Molar mass of an incipient soot particle \\
\hline$N_{A}$ & Avogadro number \\
\hline$N_{p}$ & Number of primary particles per aggregate \\
\hline$b_{\text {nuc }}$ & Normalized soot radical concentration \\
\hline$d_{c}$ & Diameter of the fractal aggregates \\
\hline$d_{p}$ & Particle diameter \\
\hline$d_{\text {prim }}$ & Primary particles diameter \\
\hline$k_{B}$ & Boltzmann constant \\
\hline $\bar{v}$ & Gas velocity \\
\hline$v_{C 2}$ & $\begin{array}{l}\text { Carbon-equivalent volume of the carbon atoms number of two soot } \\
\text { precursors and two acetylene molecules }\end{array}$ \\
\hline$v_{M A X}$ & Volume of the largest particle \\
\hline$v_{M I N}$ & Volume of the smallest particle \\
\hline$v_{T}$ & Thermophoretic velocity \\
\hline$w_{i}$ & Weights \\
\hline$x_{i}$ & Abscissas \\
\hline
\end{tabular}




\begin{tabular}{|c|c|}
\hline$\eta_{\text {coll }}$ & Collision efficiency \\
\hline$T_{w, 1}$ & Activation temperature for soot oxidation by $\mathrm{OH}$ \\
\hline$T_{w, 2}$ & Activation temperature for soot oxidation by $\mathrm{O}_{2}$ \\
\hline$T_{\alpha}$ & Activation temperature for soot nucleation \\
\hline$T_{\beta}$ & Activation temperature for soot coagulation \\
\hline $\mathrm{X}$ & Mole fraction \\
\hline$\lambda$ & Gas mean free path \\
\hline$\sigma$ & Prandtl number \\
\hline$B$ & Nucleation rate \\
\hline$D$ & Turbulent diffusion coefficient \\
\hline$G$ & Rate of change of particle volume due to surface processes \\
\hline$K n$ & Knudsen number \\
\hline$M$ & Soot mass concentration \\
\hline$N$ & Soot number density \\
\hline$N x$ & Number of weights or abscissas \\
\hline$P$ & Pressure \\
\hline$R$ & Universal gas constant \\
\hline$T$ & Temperature \\
\hline$Y$ & Mass fraction \\
\hline$d$ & Particle diameter \\
\hline$k$ & Order of the moment \\
\hline$n$ & Particle number density per unit of particle volume \\
\hline$t$ & Time \\
\hline$v$ & Particle volume \\
\hline$\beta$ & Collision frequency factor \\
\hline$\mu$ & Viscosity \\
\hline$\rho$ & Gas phase density \\
\hline
\end{tabular}

Subscripts

$\begin{array}{cl}\text { coag } & \text { Coagulation } \\ \text { cond } & \text { Condensation } \\ i & \text { Particles of size classes } i \\ j & \text { Particles of size classes } j \\ n u c & \text { Nucleation } \\ \text { ox } & \text { Oxidation } \\ s & \text { Soot }\end{array}$


Superscripts

$\begin{array}{ll}c & \text { Continuum regime } \\ f & \text { Free molecular regime } \\ t & \text { Transition regime }\end{array}$

Abbreviations

CQMOM Conditional quadrature method of moments

DOM Discrete ordinates method

DQMOM Direct quadrature method of moments

EQMOM Extended quadrature method of moments

FDF Filtered density function

FPVA Flamelet/progress variable approach

HACA Hydrogen-abstraction acetylene-addition

HMOM Hybrid method of moments

LES Large eddy simulation

LHS Left-hand-side

MOM Method of moments

MOMIC Method of moments with interpolative closure

NDF Number density function

OAC Oligomers of aromatic compounds

OFR Ordinary flame radicals

OTA Optically thin approximation

PAH Polycyclic aromatic hydrocarbons

PBE Population balance equation

PCAB PAH with aliphatic branches

PCAH Peri-condensed aromatic hydrocarbons

PDF Probability density function

PGDE Particle general dynamic equation

PSDF Particle size distribution function

QMOM Quadrature method of moments

RANS Reynolds-averaged Navier-Stokes

RFPV Radiation flamelet progress variable 
RHS Right-hand-side

RSR Resonantly-stabilized radicals

RTE Radiative transfer equation

SHM Spherical harmonics method

SLFM Steady laminar flamelet model

TCI Turbulence-chemistry interactions

TRI Turbulence-radiation interactions

WSGG Weighted-sum-of-gray-gases 


\section{Introduction}

More than $80 \%$ of the globally consumed energy comes from combustion processes so combustion is crucial for our daily activities. Combustion brings multiple benefits but also negative effects that need to be properly mitigated. One of the main concerns associated with combustion processes relates to the formation of byproducts, in particular those ones involving particulate matter, commonly known as soot. Soot is mainly composed of carbonaceous particulate but other elements such as hydrogen and oxygen are also present in small quantities [1]. Some of the main factors controlling soot formation processes are flow temperature, flow pressure and fuel chemical composition. Soot morphology includes particles and aggregates ranging in size from nanometer to micrometer scales [2].

The scientific interest of a large number of recent works is on obtaining a more detailed description of the pathways leading to soot formation and its associated morphology. The mitigation of soot negative effects on both health and environment constitutes one of the main motivations for such works. Notice that exposure to soot ultrafine particles has been found both detrimental and responsible for cardiovascular and respiratory diseases [3]. Some soot precursors such the polycyclic aromatic hydrocarbons (PAH) have been reported as being carcinogenic [4]. Previous studies indicate that the morphology of soot nanoparticles determines the level of soot toxicity, especially when these particles are sized below $100 \mathrm{~nm}$. This occurs because in these sizes soot particles are more prone to interact with cell membranes. Moreover, soot particles have a direct impact on the formation of clouds and aircraft trails and they play as well a major role in climate forcing [5]. Nevertheless, not all is bad news with soot particles. For instance, in combustion processes taking place in industrial furnaces, soot formation is intentionally sought as a way to enhance heat transfer due to the thermally radiative nature of soot particles [6]. It has been previously recognized as well that progress in soot understanding is important for the development of nanomaterial synthesis, involving for instance the production of fullerenes, graphene and carbon nanotubes [5].

Experimental data [7] supports that PAH constitute precursors to soot particles. Several past efforts have been carried out to develop detailed chemical kinetic mechanisms including these aromatic species. These developments involved the study of the influence of such aromatics on the underlying soot formation related processes, gas phase species formation, nucleation, surface growth, coagulation and agglomeration. Other equally important soot mechanisms are fragmentation and oxidation, processes that decrease the total amount of soot produced in combustion processes. Even after decades of sustained research, major uncertainties remain in soot nucleation, where a transition between gas phase chemical species and particle nuclei arises [8]. 
In order to achieve an accurate description, soot formation modeling approaches must account for not only the soot related chemical kinetics, but also implement mathematical algorithms capable of capturing soot particle dynamics [9]. Soot particle sizing is also crucial for accurate predictions because particle surface has a significant role in chemistry interactions. Because of the large number of soot particles however, tracking individual particles is challenging in soot modeling [10]. A statistical description of the evolution of the soot population is often employed thus, which implies solving a population balance equation (PBE) that governs the evolution of the number density function (NDF) describing the concentration of soot particles of a given size [11]. State-of-the-art soot formation models include the method of moments (MOM) [12]-[14], the sectional approach model [15], [16] and the Monte Carlo stochastic technique [17], [18]. What differentiates the last two models from the first one is that they are capable of directly solving the resulting PBE at the expense of a relatively high computational cost. This is why those two models are more often employed when studying soot formation in laminar flames. The method of moments on the contrary utilizes a limited number of statistical moments in order to describe the NDF evolution so it is known to be more amenable for soot predictions in turbulent reacting flows [11], [19].

The present work reviews the state-of-the-art of the main soot modeling approaches used in turbulent diffusion flames. What differentiates this review work from previous ones [1], [2], [20] is that here the main emphasis is on turbulent non-premixed flames. In addition, newer soot formation models not included in previous review works are also discussed. Accordingly, after this short introduction and in order to provide the basis for the soot modeling techniques discussed here, the main soot formation mechanisms are described in Section 2. Next in Section 3 particular combustion and radiation models used in the context of soot modeling in turbulent reacting flows involving non-premixed flames are briefly discussed. Section 4 details in turn the main soot models currently available for soot predictions in turbulent diffusion flames. For the sake of clarity, the referred soot models discussed in this work are classified according to semi-empirical and detailed soot models. In the last part of this review, comparative results (Section 5) obtained using some of the soot models discussed here are presented, along with a discussion about the prospects (Section 6) for such models and conclusions (Section 7) drawn from the review work carried out.

\section{Soot formation mechanisms}

Among the different gaseous chemical species suggested as soot precursors, polyacetylenes, ionic species and PAH have been proposed as intermediates between fuel pyrolysis and soot formation. The first two lack of experimental evidence and detailed kinetics description [21]. On the contrary, PAH and their relationship with soot formation have been largely supported by 
various experimental and modeling studies [22]. In this Section 2 the main soot formation mechanisms are initially highlighted, delving into the principal pathways associated with both formation and growth of aromatic species. The last part of this section deals with the main chemical kinetic mechanisms that have been used to describe gas phase combustion processes associated with soot formation. More detailed kinetic descriptions about soot formation can be found in previous works available in literature [5], [8], [21], [23].

\subsection{Gas phase species formation}

Soot formation begins with the pyrolysis and incomplete oxidation of hydrocarbons at high temperature fuel-rich regions, leading to the formation of small gas phase species. Acetylene, one of the most abundant gaseous products [24], together with some aliphatic radicals play a key role in the formation of the first aromatic ring and its further growth. A wide variety of reactions involving mainly radical-radical and radical-molecule type interactions occurs thus before forming the first aromatic ring, i.e. phenyl or benzene. The referred radicals can be classified in two groups, ordinary flame radicals (OFR) and resonantly-stabilized radicals (RSR). OFR involve gas phase species such as methyl $\left(\mathrm{CH}_{3}\right)$, ethyl $\left(\mathrm{C}_{2} \mathrm{H}_{5}\right)$ and vinyl $\left(\mathrm{C}_{2} \mathrm{H}_{3}\right)$. RSR include in turn propargyl $\left(\mathrm{C}_{3} \mathrm{H}_{3}\right)$, allyl $\left(\mathrm{C}_{3} \mathrm{H}_{5}\right)$ and cyclopentadienyl $\left(\mathrm{C}_{5} \mathrm{H}_{5}\right)$ [8]. RSR possess a delocalized unpaired electron in their molecular structure making them more stable and abundant in flames than ordinary radicals [25]. When compared to ordinary radicals indeed, RSR both form weaker bonds with stable molecules and react with other RSR having relatively low energy barriers resulting in relatively high kinetic rates. Weaker bonds within RSR means that RSR-O dissociation processes will dominate over isomerization ones, thus explaining RSR resistance to $\mathrm{O}_{2}$ oxidation. For instance, oxidation kinetics between allyl or propargyl and $\mathrm{O}_{2}$ are two to five orders of magnitude slower than oxidation rates between vinyl and $\mathrm{O}_{2}[26]$. Which of these radical species ends up playing leading roles depends on their relative concentration, the fuel molecular composition and the local prevailing combustion conditions. Nevertheless, some reactions found in almost every combustion process stand out. These include recombination of propargyl radicals, $\mathrm{n}-\mathrm{C}_{4} \mathrm{H}_{3}$ or $\mathrm{n}-\mathrm{C}_{4} \mathrm{H}_{5}$ reaction with acetylene, and cyclopentadienyl reaction with propargyl that leads to the formation of benzene and two $\mathrm{H}$ atoms [21].

The next step in the formation of the gaseous chemical species accounted for as soot precursors relates to the formation of larger aromatic molecules. One well known mechanism is the hydrogen-abstraction acetylene-addition (HACA) originally proposed by Frenklach and Wang [27]. This mechanism essentially consists of a two-step repetitive reaction. First, a reaction between an aromatic molecule and a hydrogen atom leads to both the aromatic activation and the formation of a hydrogen molecule. Then an acetylene molecule is added to the free radical site of the aromatic ring or compound [22]. Following the benzene or phenyl formation, a two-step HACA sequence produce the formation of naphthalene. Subsequent HACA reactions form larger 
molecules of fused rings, such as phenanthrene, pyrene and coronene. At this stage, some stable PAH known as stabilomers are identified, which are capable of surviving fragmentation at high temperatures [5]. Within the stabilomers group, peri-condensed aromatic hydrocarbons (PCAH) are formed. These chemical species consist of fused six-membered ring molecules containing only pi bonds between carbon atoms. As highlighted by Wang [5], the HACA mechanism satisfies the thermodynamics and kinetic requirements of soot formation processes, being the reversibility of the reaction sequence a paramount characteristic. A gradual decrease of Gibbs free energy takes place throughout the aromatics molecular growth, until the formation of stabilomers, when the reaction becomes irreversible so the growth of larger aromatics is promoted [28]. Nonetheless, due to the $\mathrm{H}$-abstraction energy barrier, when compared to experimental observations, the HACA mechanism presents relatively slow rates for the last stages of the aromatics molecular growth [29]. In addition to six-membered ring molecules, five membered-ring species can also be formed through a sequence of acetylene addition [21]. Notice that five-membered rings found in larger aromatic molecules periphery contributes to molecules curvature [30].

Several other pathways for PAH growth have been proposed over the years, which include reactions between PAH and phenyl or RSR such as propargyl or cyclopentadienyl. Notice that RSR can react as well with each other to form molecules that differ from benzene. For instance, recombination of cyclopentadienyl leads to naphthalene formation [21]. A pathway recently proposed by Johansson et al. [31] describes a chain reaction between an RSR and acetylene or vinyl radical that leads to the formation of a compound conserving radical characteristics, hence to the formation of a larger RSR. RSR chain reactions also lead to the formation of sigma bonded cross-linked aromatic rings, designated as oligomers of aromatic compounds (OAC) by D'Anna and Sirgnano [8]. OAC can also contain aliphatic branches or oxygen inclusions that match with atomic force microscopy observations [30]. It is worth noticing that, similarly to the benzene formation step, the described pathways may occur simultaneously, and the prevalence of each pathway depends on both flame chemistry and local temperature [21].

\subsection{Nucleation}

The soot nucleation mechanism results from the collision and physical coalescence of large aromatic molecules following their dimerization. More specifically, once PCAH and OAC have achieved moderate sizes, a transition from the gas phase to the first particle nuclei takes place. Nucleation remains as the least understood soot formation stage and, although the soot nucleation pathways highlighted in this section are supported by experimental evidence, a definite nucleation mechanism need to be determined yet. Recently proposed nucleation pathways involve the clustering of PCAH and OAC, or even the assembly of both of them [8]. On the one hand, PCAH have a planar structure and readily form parallel stacks bonded by van der Waals forces resulting in a turbostratic structure. Clustering of small PAH such as naphthalene or pyrene is possible at 
low temperatures only. At average flame temperatures however, a minimum size of a circumcoronene (666u) is required for a feasible PAH dimerization [21]. Nevertheless, PAH of these sizes are hardly experimentally observed. This is because there are several isomers of moderate sized PAH and large PAH that readily form soot leading to low larger PAH concentrations. As a consequence, moderate sized PAH identification is a difficult task. On the other hand, OAC dimerize by sigma bonds and can cluster with a wide variety of hydrocarbons species. Dehydrogenation at the edges of the clustered species can add extended conjugation, stabilizing in this way the OAC dimer. Dimerization together with dehydrogenation release a significant amount of energy, reducing the reactions reversibility [31]. Major advantages of this soot nucleation pathway are the reduced energy barrier and the way it allows interactions with both PAH radical and hydrocarbons of a wide range of sizes, including stabilized PAH and unsaturated aliphatic molecules. As emphasized in literature however, more research work is needed in order to obtain detailed reaction rates for the referred nucleation related processes.

In previous works [32], [33], the inception rate of three soot intermediates that can be included in $\mathrm{OAC}$, (i) $\mathrm{PCAH}$, (ii) $\mathrm{PAH}$ with aliphatic branches (PCAB) and (iii) aromatic molecules linked by aliphatic chains, have been particularly studied. Findings from these works indicate that $\mathrm{PCAB}$ have the fastest inception rates and suggest that the presence of aliphatic chains adds internal degrees of freedom that accommodate the associated collision energy. Aliphatic branches have therefore a significant effect on promoting clusters formation. Another proposed nucleation pathway involves the formation of fullerene-like structures that can act as inception cores. This pathway has been ruled out however as a dominant mechanism. This is because the associated reaction rates are too slow and particles morphology would result in a monomodal distribution, which contradicts the soot bimodal PSDF frequently observed in experiments [5].

\subsection{Particle growth}

This stage of soot formation is related to soot particles growth in both mass and size resulting from particle nuclei interactions. Particle growth mechanisms can be summed up as (i) particle surface growth, (ii) particle coalescence and (iii) particle agglomeration. The first mechanism involves mass additions through reactions taking place at the particle surface. The above discussed gaseous chemical species are added to the particle nuclei surface that condense next. Similar to the gas phase molecular growth, one of the predominant mechanisms here is HACA, through which the reactant side at the particle edge is firstly activated by dehydrogenation, and an acetylene molecule is subsequently added to the free site [5]. Several variants for the HACA mechanism have been proposed. This has stemmed from the persistent experimental evidence that suggests both the presence of aliphatic molecules over the particles surface [31] and the growth of soot nuclei in flame environments lacking of $\mathrm{H}$ atoms [5]. In this worth noticing that 
dehydrogenation reactions can also begin with a radical interaction, which involves radical species such as methyl, ethynyl or propargyl [21]. In addition to acetylene, PAH can also bind to particle surface. Besides flame conditions, soot particles morphology is also important at this point for determining the way in which reactions proceed. Coalescence describes in turn the physical collision of particles and their union involving the elimination of the associated boundary. As a result, a spherical structure is formed and the particle total surface decreases. Finally, soot particle agglomeration, involving the sticking of particles in a contact point, results in the formation of fractal structures. As particles coalesce and surface decreases, surface growth processes become less predominant than coalescence ones [34].

\subsection{Fragmentation and Oxidation}

Fragmentation in this context refers to the physical division of soot aggregates and particles, possibly returning to an earlier stage in soot formation. Fragmentation depends primarily on flame temperature and can occur in every stage of soot formation, leading to smaller agglomerates, smaller clusters or even smaller PAH [8]. Oxidation is defined in turn as chemical reaction processes occurring at soot particles surface due to the attack of either an $\mathrm{O}$ molecule or an $\mathrm{OH}$ radical, resulting in soot mass reduction [35]. Fragmentation induced by oxidation is also possible and consists in the division of soot aggregates as oxidation reactions take place at their contact points, due to the removal of carbon atoms and the weakening of the aggregate structure [21]. Notice that fragmented products act as soot intermediates for the above discussed mechanisms. Fragmentation and oxidation processes are consequently of crucial importance for determining soot particles final size and mass.

\subsection{Chemical kinetic mechanisms}

Over the years several chemical kinetic mechanisms have been developed for predicting soot formation in combustion processes. The size of the referred mechanisms, in terms of number of chemical species and reactions, ranges from a few species and reactions to tens/hundreds of species and hundreds/thousands of reactions (cf. Table 1). It is worth noticing first here that kinetic mechanisms serve as a library containing information on the chemical species and their associated chemical reactions accounted for, as well as thermodynamic data often mechanismspecific. Kinetic mechanisms are usually classified as detailed, skeletal and reduced. This classification depends mainly on the number of chemical species and reactions characterizing each mechanism. Skeletal and reduced kinetic mechanisms are derived from detailed ones for a particular physico-chemical system, so they are valid for a specific range of mixture properties that are more restrictive, when compared to the baseline detailed chemical model. These mechanisms are usually employed in studies involving complex configurations simulations such as those related to practical combustion devices [36]. Solving the numerous kinetic rates and 
reactions of a detailed kinetic mechanism involves a relatively high computational cost and that is where the importance of reduced mechanisms lies. In particular, when modeling soot formation and oxidation processes, detailed mechanisms are required to properly describe the various intermediates reactions and the potential pathways leading to soot formation. The CHEMKIN ${ }^{\circledR}$ format is often used as a standard for the development and use of these detailed kinetic mechanisms. Information contained in each mechanism include chemical species, reactions, kinetic parameters, thermodynamic coefficients and transport properties. Currently there is a wide variety of chemical kinetic mechanisms openly available for modeling reacting flows. Table 1 summarizes some of the main kinetic mechanisms used over the years for modeling soot formation in gaseous hydrocarbon fuels related combustion processes. This table highlights in particular the kinetic mechanisms number of chemical species and reactions, the largest gaseous species involved, and the main fuels and configurations accounted for during the development of the referred mechanisms.

Table 1. Summary of main chemical kinetic mechanisms used in soot formation modeling.

\begin{tabular}{|c|c|c|c|c|c|c|}
\hline $\begin{array}{l}\text { Kinetic } \\
\text { Mechanism }\end{array}$ & $\begin{array}{l}\mathrm{N} \text { of } \\
\text { species }\end{array}$ & $\begin{array}{l}\mathrm{N} \text { of } \\
\text { reactions }\end{array}$ & $\begin{array}{l}\text { Largest } \\
\text { gaseous } \\
\text { species }\end{array}$ & Fuels & $\begin{array}{l}\text { Configurations used for } \\
\text { validation }\end{array}$ & References \\
\hline DLR & 112 & 939 & $\mathrm{C} 20 \mathrm{H} 12$ & $\mathrm{C} 1-\mathrm{C} 4$ & $\begin{array}{l}\text { Laminar premixed flames } \\
\text { Shock tube, counterflow and } \\
\text { spherical flame } \\
0.026-10 \text { bar }\end{array}$ & $\begin{array}{l}\text { Slavinskaya et } \\
\text { al., } 2009 \text { and } \\
2019 \text { [37], [38] }\end{array}$ \\
\hline PoliMi & $452 *$ & 24041 & $\mathrm{C} 20 \mathrm{H} 16$ & $\mathrm{C} 1-\mathrm{C} 10$ & $\begin{array}{l}\text { Laminar premixed flames } \\
0.03-1 \mathrm{~atm}\end{array}$ & $\begin{array}{l}\text { Pejpichestakul, } \\
2018[39]\end{array}$ \\
\hline Aramco 3.0 & 120 & 450 & $\mathrm{C} 16 \mathrm{H} 10$ & Syngas & $\begin{array}{l}\text { Laminar premixed flames } \\
\text { Rapid compression machine } \\
(\mathrm{RCM}) \text { and Shock tube } \\
1-70 \text { bar / HT }\end{array}$ & $\begin{array}{l}\text { Keromnes et al., } \\
2013[40]\end{array}$ \\
\hline KM2 & 202 & 1351 & $\mathrm{C} 24 \mathrm{H} 10$ & $\mathrm{C} 1-\mathrm{C} 4$ & $\begin{array}{l}\text { Laminar premixed flat } \\
\text { flame and counterflow } \\
\text { diffusion flame } \\
0.026-1 \text { bar }\end{array}$ & $\begin{array}{l}\text { Wang et al., } \\
2013[41]\end{array}$ \\
\hline NBP & 149 & 1651 & $\mathrm{C} 18 \mathrm{H} 10$ & $\begin{array}{l}\mathrm{CH} 4- \\
\text { isoC } 8 \mathrm{H} 18\end{array}$ & $\begin{array}{l}\text { Isochoric and adiabatic } \\
\text { homogenous reactor } \\
\text { Laminar premixed flat } \\
\text { flame and counterflow } \\
\text { diffusion flames } \\
\text { 1-10 bar / HT }\end{array}$ & $\begin{array}{l}\text { Blanquart et al., } \\
\text { 2009[42]; } \\
\text { Narayamaswam } \\
\text { y et al., } 2010 \\
\text { [43] }\end{array}$ \\
\hline D’Anna M3 & $167 *$ & 1887 & $\mathrm{C} 16 \mathrm{H} 10$ & $\mathrm{C} 2 \mathrm{H} 4$ & $\begin{array}{l}\text { Laminar premixed flame } \\
\text { and coflow diffusion flame } \\
1 \text { bar }\end{array}$ & $\begin{array}{l}\text { D’Anna, } 2008 \\
{[44]} \\
\text { D’Anna and } \\
\text { Kent, } 2006 \text { [45] }\end{array}$ \\
\hline USCII & 111 & 784 & $\mathrm{C} 10 \mathrm{H} 8$ & $\begin{array}{l}\text { Syngas/ } \\
\text { C1-C4 }\end{array}$ & $\begin{array}{l}\text { Laminar premixed flames } \\
\text { Shock tube, flow reactor, } \\
\text { spherical flame } \\
0.79-1 \text { bar } / \mathrm{HT}\end{array}$ & $\begin{array}{l}\text { Wang et al., } \\
2007[46]\end{array}$ \\
\hline
\end{tabular}




\begin{tabular}{|c|c|c|c|c|c|c|}
\hline MIT & $295^{*}$ & 6654 & $\mathrm{C} 24 \mathrm{H} 12$ & $\mathrm{C} 6 \mathrm{H} 6 / \mathrm{O} 2 / \mathrm{Ar}$ & $\begin{array}{l}\text { Laminar premixed flame } \\
\text { LP }\end{array}$ & $\begin{array}{l}\text { Richter et al., } \\
2005 \text { [47]; } \\
\text { Ergut et al., } \\
2006 \text { [48] }\end{array}$ \\
\hline $\mathrm{ABF}$ & 92 & 527 & $\mathrm{C} 16 \mathrm{H} 10$ & $\mathrm{C} 2$ & $\begin{array}{l}\text { Laminar premixed flames } \\
\text { Porous plug flat burner. } \\
0.12-10 \text { bar }\end{array}$ & $\begin{array}{l}\text { Appel et al., } \\
2000[9]\end{array}$ \\
\hline
\end{tabular}

(*) Includes gas phase chemical species and BINs representing soot particles and aggregates.

From Table 1 it is worth emphasizing first that, although ABF [9] is not a novel kinetic mechanism, it has been widely employed as a reference model in combustion simulations due to its detailed description on C2- fuels reactions and PAH growth. DLR [38] features in turn detailed pathways related to both acetylene and PAH precursors formation. Aramco 3.0 [40] presents a relatively low number of chemical reactions so it could be an affordable model to use in complex fluid flow situations. This last mechanism developed for syngas includes a detailed description of $\mathrm{H}_{2}$ and $\mathrm{CO}$ formation and contains aromatic species up to pyrene. NBP [43] can be used for modeling not only gaseous fuels but also gasoline surrogate ones. KAUST also known as KM2 mechanism has been developed with focus on small hydrocarbon fuels [41] and describes in a detailed way the PAH chemistry up to coronene $\left(\mathrm{C}_{24} \mathrm{H}_{10}\right)$. When compared to previous kinetic mechanisms indeed, KAUST leads to results that closer agree with PAH experimental data. Even though it does not describe the formation of PAH with more than 10 carbon atoms, USC II has been also included in Table 1. This has been done because it has been shown that this mechanism leads to relative good predictions in ethylene flames [41], so it may be useful when employing simplified soot formation models such as the semi empirical ones.

Lumped approaches frequently employed in chemical kinetic mechanisms reduction processes can also be applied for describing both PAH and soot formation. Accordingly, groups of PAH isomers, i.e., PAH having similar mass (amu), $\mathrm{H} / \mathrm{C}$ ratios and diameters $(\mathrm{nm})$, can be classified in BINs [48]. BINs are treated as gas phase species and their kinetic constants are derived from gas phase reactions with similar pathways [24]. Chemical kinetic mechanisms including BINs allow then describing $\mathrm{PAH}$ growth, particles and aggregates formation and surface reactions. Three of these kinetic mechanisms featuring BINs thus, developed by the CRECK modeling group, MIT [47], D’Anna M3 [44] and PoliMi [39], have been also included in Table 1. For a further insight of detailed mechanisms available for different gaseous and liquid alkane fuels, the reader is referred to the review work by Konnov and coworkers [49].

Most of the kinetic mechanisms included in Table 1 have been developed accounting for premixed flames related configurations. Chemical kinetic rate constants associated with elementary reactions depend primally on molecular structure and not on their measurement conditions, apart from temperature and sometimes pressure [36]. So the referred kinetic mechanisms could be also employed for modeling diffusion flames but their suitability needs to 
be assessed. The fuels for which a given mechanism has been developed is another significant aspect that must be considered when comparing the data given in this table. For instance, reaction pathways related to $\mathrm{C} 3$ and $\mathrm{C} 4$ species formation leading then to the formation of aromatics can significantly differ in low and high molecular weight hydrocarbon fuels [43]. Flame configurations and operating conditions accounted for in the development of chemical kinetic mechanisms cover different situations representative of actual combustion devices. Accordingly, high pressure and temperature conditions are addressed using shock tube and rapid compression machines (RCM). Laminar burning velocities and ignition delay times are studied in turn in spherically expanding, counterflow and premixed planar flames, whereas perfectly stirred reactors (PSR) are used for studying gas phase oxidation and pyrolysis [36].

Chemical kinetic mechanisms are developed without taking into account turbulencechemistry interactions. Nevertheless, since most devices of engineering interest involve turbulent flows, the implications of using such kinetic mechanisms in turbulent combustion processes burning fuels such as hydrogen, methane, propane, $n$-dodecane have been extensively studied in the past [50]-[53]. The influence of turbulence on chemical pathways for light and heavy fuels has been also studied [54],[55]. In particular, it has been determined that because of turbulence correlations between species concentrations, temperatures, and reaction rates can be altered due to flames unstable stretching and internal mixing. In addition, the relative contributions to temperature of different reactions vary due to diffusion effects and the differences in species concentrations in a given place or isotherm. Furthermore, in case of intense turbulence, some of the chemical species included in chain branching reactions can be transported by fast convection and modify the associated chemical reactions [51]. It is important therefore to further study the influence of different chemical kinetic mechanisms on soot formation predictions carried out in turbulent diffusion flames.

\section{Combustion and radiation modeling closures for soot modeling}

Both combustion and radiation models used when modeling soot formation processes in turbulent reacting flows are briefly addressed in this section.

\subsection{Combustion modeling approaches}

Combustion models have a significant impact on soot predictions due to the strong coupling between chemistry, turbulence and soot formation. Soot predictions depend indeed on both the soot model and the reacting flow thermochemical state, which is determined by the combustion model utilized. Particularly soot inception location and soot evolution are rather sensitive to the combustion model [56]. For instance, even small upstream errors in temperature, which are within the experimental uncertainty, can lead downstream to errors in the soot volume fraction up to $30 \%$ 
[57]. Modeling frameworks currently used for studying turbulent reacting flows are usually based on large eddy simulation (LES) [56], [58], [59]. In LES-based modelling, large-scale, geometrydependent motions are resolved, whereas small-scale turbulent structures are modeled. When predicting minor chemical species and pollutants in turbulent reacting flows, the associated accuracy typically required cannot be achieved using Reynolds-averaged Navier-Stokes (RANS) simulations [60]. So this is the main reason why in such situations LES models are preferred over RANS ones. There are two main combustion modeling approaches used in soot predictions in turbulent non-premixed flames, (i) flamelet-based models and (ii) transported probability density function (PDF) ones.

The flamelet approach first introduced by Peters [61] considers a turbulent diffusion flame as an ensemble of laminar flamelets [61]. In the steady laminar flamelet model (SLFM) in particular, the non-premixed flame structure is a priori computed in mixture fraction space by solving the steady flamelet equations. The so obtained solutions are then parameterized with a reduced set of variables (mixture fraction $\mathrm{Z}$, scalar dissipation rate $\chi$ ) and stored in a database that is accessed during LES simulations [58]. SLFM reproduces relatively well the reference experimental data in terms of temperature and mixture fraction. For predictions of slow chemical or physical processes however, like PAH formation, unsteady effects need to be accounted for so the full unsteady flamelet equations should be solved [62], [63]. The flamelet/progress variable approach (FPVA) constitutes a variant of the flamelet approach under discussion. In the FPVA, which was proposed by Pierce and Moin [64] as a model for turbulent non-premixed combustion in LES, instead of using the scalar dissipation rate as a flamelet library parameter, a reaction progress variable defined in terms of a linear combination of major reaction product mass fractions is used for the parameterization [64]. FPVA potentially gives a better description of flame local extinction and reignition phenomena and flame lift-off [65], [66]. This particular approach has been further extended to account for radiation effects leading to the radiation flamelet progress variable (RFPV) model, where an additional coordinate is included in the mapping process [56]. Some recent soot-related works have used the RFPV model for both modeling combustion and studying the contribution from individual PAH to soot formation [62], [67]. Overall, flamelet-based combustion models have been extensively used in the past for modeling turbulent non-premixed flames due to their notable advantages in terms of reduced computational cost. They probably cannot capture however the high sensitivity of soot formation and growth processes to the history of turbulent gas-phase compositions encountered in actual flames [56].

Probability density function (PDF) methods, or filtered density function (FDF) ones as they are known in LES contexts, offer compelling advantages for modeling chemically reacting turbulent flows. This is because they provide an effective solution to the closure problems that 
arise from averaging/filtering, in the instantaneous governing equations, both nonlinear chemical source terms and terms corresponding to other one-point physical processes [68]. The particular formulation used for modeling turbulent reacting flows is known as transported PDF method. This particular approach involves solving a transport equation for the joint PDF including at least the scalars needed to close the chemical source terms. The PDF transport equation solved is in general high-dimensional requiring thus the use of Monte Carlo techniques. Both Lagrangian and Eulerian Monte Carlo approaches have been utilized for solving this PDF transport equation. The current mainstream involves using Lagrangian methods [69], which rely on the use of notional particles that evolve according to stochastic ordinary differential equations. Following this approach, mixing models are required for the purposes of closing the PDF transport equations [70]. In short, transported PDF methods have the capability for accurate predicting complex turbulent reacting flows [71], [72]. Compared to flamelet-based models however, PDF methods computational cost is relatively high. This occurs because in this case during modeling there is a direct treatment of chemical kinetics, which can include tens or hundreds of chemical species and thousands of chemical reactions. When modeling combustion processes indeed, in order to accurately capture both soot inception and formation of soot precursors such as acetylene and $\mathrm{PAH}$, chemical mechanisms accounting for all major pathways of PAH formation need to be utilized [56]. Recent works [73], [74] include the use of transported PDF methods in conjunction with detailed soot formation models such the method of moments and the sectional ones. These soot formation models will be detailed in Section 4.

\subsection{Radiation modeling approaches}

Radiation is a vast subject by itself so an in-depth discussion about it is out of the scope of this work. Accordingly, this section does not attempt to provide a review of the radiation phenomenon but merely to list the radiation models mostly used when predicting soot formation in turbulent flames. The focus here will be therefore restricted to the soot modeling point of view only. It is worth noticing first that chemical reactions influence the associated fluid flow through local changes in flow temperature and hence in flow density, whereas convective and molecular transport processes influences chemistry by changing the flame structure and hence the heat release rate [75]. These effects are known as turbulence-chemistry interactions (TCI). In a similar fashion, in combustion processes featuring significant thermal radiation effects, such as those arising in sooting flames, turbulence-radiation interactions (TRI) appear and they need to be properly accounted for. The radiation term in the instantaneous energy equation, or in the RANS or LES approaches related ones, involves the difference of two phenomena, (i) absorption and (ii) emission. The latter depends on local flow properties such as flow temperature and radiating species partial pressures, and it is a nonlinear function of temperature and wavelength via the associated spectral dependency of the participating medium absorptivity. The former term in turn 
associated with the absorption of incoming radiation depends on a nonlocal quantity such as the radiative intensity, which reckons on flow composition everywhere within the medium [75]. Thus, the radiative transfer equation (RTE) needs to be solved in order to obtain the local radiative intensity. As highlighted by Modest and Haworth [75] absorption related TRI are particularly difficult to assess because local radiative intensity fluctuations are coupled to flow properties of the whole medium.

Radiating chemical species such as $\mathrm{CO}_{2}$ and $\mathrm{H}_{2} \mathrm{O}$ and particulate matter such as soot, which are usually present in turbulent reacting flows, emit and absorb thermal radiation over a radiation spectrum composed by a large number of spectral bands. In detailed radiation modeling approaches such as the spectral line-by-line one [76], each spectral band is divided into thousands of wavelength intervals each one featuring an individual absorption coefficient value. The whole spectrum results then in hundreds of thousands of wavelength intervals where the RTE needs to be solved [77]. Since this accurate approach involves a prohibitive computational cost for engineering applications, over the years different modeling alternatives have been proposed. These lower cost modeling approaches include traditional (accounting for averaged "line-ofsight" gas emissivities and transmissivities) and modern (k-distributions) band models, and global radiation ones. A rather simplified approach often used in combustion calculation is the one based on the optically thin approximation (OTA), where only radiation emission is accounted for and self-absorption is disregarded. OTA allows predicting the behavior of several laboratory flames reasonably well but presents shortcomings when used in industrial applications related flames [75]. Global radiation models in turn, such as the weighted-sum-of-gray-gases (WSGG) first introduced by Hottel [78], integrate over the entire spectrum before solving the RTE, significantly reducing thus the RTE evaluations number [75]. Variants of the WSGG method such as the spectral-line-based WSGG, which is based on the use of high-resolution radiation databases, have also been developed. Several efforts have been devoted as well to the development of solution methods to the RTE. Two of the most popular methods include the spherical harmonics (SHM) and the discrete ordinates (DOM) ones [76]. SHM, whose lowest order implementation is known as P1 (approximation) method, decouples spatial and directional dependencies by expanding the radiative intensity into a series of spherical harmonics [75]. DOM is in turn an extension of the finite-difference method for spatial discretization, involving in particular a discretization in the angular direction. Monte Carlo methods may be used for RTE integration, as they exhibit significant advantages over the referred classical approaches. Among these, the most relevant are those related to the fact that Monte Carlo methods are not limited to OTA, enable to incorporate complex computational domains straightforwardly, and deal with general boundary conditions.

A detailed treatment of radiative transfer processes occurring in turbulent flames is indeed computationally expensive. In order to include in such flames radiation effects without 
significantly increasing the associated computational burden therefore, simplified radiation modeling approaches are usually employed. Radiation models used in the past in the context of soot modeling in turbulent reacting flows include optically-thin approximation based ones [56], [57], [59], [67], [74], [79]-[81], WSGG [82]-[86], SHM (P1 approximation) [86]-[89] and DOM [89]-[91]. One should note as well that there are several past research efforts involving soot formation [19], [72], [92]-[97] where radiation modeling approaches have not been accounted for. It should be emphasized that radiation models may be crucial to the description of turbulent sooting flames because if radiative energy transport is neglected radiation computed flame temperatures may be overestimated by hundreds of degrees. On the contrary, using an inadequate radiation model could result in large underestimations of flame temperatures. As soot and its precursors directly depend on flame temperatures, it is paramount to predict properly these temperatures in order to obtain accurate soot predictions. It may be concluded from this brief discussion of the subject that modeling TRI and in particular radiation absorption make the associated modeling process a formidable task. For detailed discussions about radiative heat transfer in thermal systems in general and in turbulent combustion ones in particular the interested reader is referred to references [75], [76]. A relatively recent review [98] about radiation effects from both measurement and modeling points of view is also referred for these purposes.

\section{Soot modeling in turbulent combustion}

Over the years different classifications have been utilized for soot formation models. Kennedy [1] classified them for instance as (i) empirical correlations, (ii) semi-empirical models and (iii) models with detailed chemistry. Notice however that Kennedy's work was mainly focused on empirical and semi-empirical models due to the natural limitations of the time and the lack of studies in detailed models. More recently soot models have been classified as semiempirical non-precursor and precursor models, and detailed models [2]. In the present work thus, following Rigopoulus [2], soot models are classified in two categories only, (i) semi-empirical soot precursor models and (ii) detailed ones. This has been done because most of the recent studies carried out in the field of soot formation are mainly focused on these two categories. A particular emphasis is put here on detailed soot formation models used when modeling turbulent diffusion flames.

\subsection{Semi-empirical soot precursor models}

Semi-empirical models used for predicting soot formation generally involve solving transport equations for both soot mass fraction, Eq. (1), and nuclei concentration, Eq. (2) [99],

$$
\frac{\partial \rho Y_{s}}{\partial t}+\nabla \cdot(\rho \bar{v}) Y_{s}=\nabla \cdot\left(\frac{\mu_{t}}{\sigma_{s}} \nabla Y_{s}\right)+\frac{d M}{d t}
$$


$\frac{\partial \rho b_{n u c}}{\partial t}+\nabla \cdot(\rho \bar{v}) b_{n u c}=\nabla \cdot\left(\frac{\mu_{t}}{\sigma_{n u c}} \nabla b_{n u c}\right)+\frac{1}{N_{n o r m}} \frac{d N}{d t}$

In Eqs. (1) and (2), $Y_{S}$ stands for soot mass fraction, $b_{n u c}$ is the normalized soot radical concentration and $\sigma$ is the Prandtl number. In addition, $\rho$ represents density, $\mu$ viscosity, and $M$ and $N$ are the soot mass concentration and soot number density, respectively.

Two-step soot formation models usually account for physical and chemical mechanisms. As it may be easily inferred from the discussions carried out in Section 2, they do so however in a simplified way. Some of the soot formation mechanisms commonly accounted for in these simplified modeling approaches include nucleation, surface growth, coagulation and oxidation. When compared to previous models such as empirical or temperature-based semi-empirical ones, the referred two-equation soot models have been an important step towards the development in recent years of more precise soot models, It is worth noticing that two-equation models generally involve the use of constants that are experimentally determined, making thus the model semiempirical and limiting its capability for predicting soot formation in situations different to those taken into account in the associated experiments.

One frequently implemented soot model is that due to Brookes and Moss [100], which directly solves transport equations for $N$ and $M$ [101],

$$
\begin{aligned}
& \frac{d N}{d t}=\left(\frac{d N}{d t}\right)_{\text {nucleation }}-\left(\frac{d N}{d t}\right)_{\text {coagulation }}, \\
& \frac{d M}{d t}=\left(\frac{d M}{d t}\right)_{\text {nucleation }}+\left(\frac{d M}{d t}\right)_{\text {surface growth }}-\left(\frac{d M}{d t}\right)_{\text {oxidation }} .
\end{aligned}
$$

where each of the right-hand-side (RHS) terms appearing in Eqs. (3) and (4) are computed as,

$$
\begin{aligned}
& \left(\frac{d N}{d t}\right)_{\text {nucleation }}=C_{\alpha} \cdot N_{A}\left(\frac{X_{C 2 H 2} P}{R T}\right)^{l} e^{-\frac{T_{\alpha}}{T}} \\
& \left(\frac{d N}{d t}\right)_{\text {coagulation }}=C_{\beta} \cdot\left(\frac{24 R T}{\rho_{\text {soot }} N_{A}}\right)^{0.5} \cdot d_{p}^{0.5} \cdot N^{2}, \\
& \left(\frac{d M}{d t}\right)_{\text {nucleation }}=C_{\alpha} \cdot M_{p}\left(\frac{X_{C 2 H 2} P}{R T}\right)^{l} e^{-\frac{T_{\alpha}}{T}} \\
& \left(\frac{d M}{d t}\right)_{\text {surface growth }}=C_{\gamma} \cdot\left(\frac{X_{C 2 H 2} P}{R T}\right)^{m} e^{-\frac{T_{\gamma}}{T}} \cdot\left[(\pi N)^{\frac{1}{3}} \cdot\left(\frac{6 M}{\rho_{s} N_{A}}\right)^{\frac{2}{3}}\right]^{n},
\end{aligned}
$$




$$
\begin{aligned}
\left(\frac{d M}{d t}\right)_{\text {oxidation }}= & C_{\text {oxid }} \cdot \sqrt{T}(\pi N)^{\frac{1}{3}} \cdot\left(\frac{6 M}{\rho_{s} N_{A}}\right)^{\frac{2}{3}} \\
& \cdot\left[C_{w, 1} \cdot \eta_{\text {coll }}\left(\frac{X_{O H} P}{R T}\right) e^{-\frac{T_{w, 1}}{T}}+C_{w, 2} \cdot\left(\frac{X_{O 2} P}{R T}\right) e^{-\frac{T_{w, 2}}{T}}\right]
\end{aligned}
$$

In Eqs. (5)-(9), $C_{\alpha}, C_{\beta}, C_{\gamma}, C_{\text {oxid }}$ are respectively empirical rate scaling factors for nucleation, coagulation, surface growth and oxidation. $C_{w, 1}$ and $C_{w, 2}$ are model constants associated with $\mathrm{OH}$ and $\mathrm{O}_{2}$ oxidations, respectively. $\eta_{\text {coll }}$ is in turn a collisional efficiency parameter. Similarly, $T_{\alpha}$, $T_{\gamma}, T_{w, l}$ and $T_{w, 2}$ are activation temperatures for soot inception, surface growth and so on. Also $l$, $m, n$ are model parameters adjusted to give a better data fit. $X_{C 2 H 2}$ represents in turn acetylene mole fraction, $N_{A}$ is the Avogadro number and $M_{P}$ is the molar mass of an incipient soot particle. Finally, $d_{P}$ stands for the mean soot particle diameter. Notice that in this model acetylene is the only soot precursor accounted for and the model constants have been determined from a diffusion methane/air-based flame. Moreover, soot particles are assumed to have a spherical shape and a monodisperse size distribution.

An extended semi empirical soot model was developed by Hall and coworkers [102] by adding two and three-ringed aromatics to the soot nucleation rate so the nucleation related terms read as follows,

$$
\begin{aligned}
\left(\frac{d N}{d t}\right)_{\text {nucleation }}= & 8 \cdot C_{\alpha, 1} \cdot \frac{N_{A}}{M_{p}}\left[\rho^{2}\left(\frac{Y_{C 2 H 2}}{W_{C 2 H 2}}\right)^{2} \cdot \frac{Y_{C 6 H 5} W_{H 2}}{W_{C 6 H 5} Y_{H 2}}\right] e^{-\frac{T_{\alpha, 1}}{T}}+8 \cdot C_{\alpha, 2} \\
& \cdot \frac{N_{A}}{M_{p}}\left[\rho^{2}\left(\frac{Y_{C 2 H 2}}{W_{C 2 H 2}}\right)^{2} \cdot \frac{Y_{C 6 H 6} Y_{C 6 H 5} W_{H 2}}{W_{C 6 H 6} W_{C 6 H 5} Y_{H 2}}\right] e^{-\frac{T_{\alpha, 2}}{T}}
\end{aligned}
$$

where sub-indices 1 and 2 refer to $\mathrm{C}_{10} \mathrm{H}_{7}$ and $\mathrm{C}_{14} \mathrm{H}_{10}$, respectively.

$$
\left(\frac{d M}{d t}\right)_{\text {nucleation }}=\frac{M_{p}}{N_{A}} \cdot\left(\frac{d N}{d t}\right)_{\text {nucleation }} .
$$

Other semi-empirical soot models describe in a more detailed way both soot formation and oxidation [103]. For instance, the two-step model proposed by Lindstedt and coworkers [104], [105] improves the description of the chemical and physical soot mechanisms by adding soot aggregation to the modeled mechanisms. A distinct feature of this last model is its capability for being coupled with detailed chemical descriptions, rather than reduced ones. This two-step model also assumes a mean particle diameter, an thus a monodisperse PSDF [73]. Using semi-empirical models frequently involves the adjustment of the empirical model constants for a wider fuel application and to correctly fit the experimental data [106]. In recent years, the implementation of semi-empirical models has been related to the numerical modeling of methane/air flames [99], [107], ethylene/air diffusion flames [108], methane and heptane turbulent diffusion flames [109], and sooty kerosene/air diffusion flames [86]. Most of these research efforts accounted for radiation effects and their influence on flame temperature and chemical species formation. As 
discussed in Section 1, in the years to come, determining soot particles morphology will be crucial for properly describing how soot particles of a particular size interact with each other and thus how soot formation occurs. Although using semi-empirical models involves a relatively low computational cost, the fact that they are not capable of dealing with soot particles morphology and soot predictions in conditions that are different to those ones accounted for during their development represents a big limitation.

\subsection{Detailed models}

Detailed soot formation models rely on the spatial and temporal evolution of the particle size distribution function (PSDF) of soot. This means that the population balance equation (PBE) determining the dynamics of a polydisperse particulate system is directly or indirectly solved. The PBE, or particle general dynamic equation (PGDE) as it is sometimes referred to, describes both soot particles internal processes such as nucleation, condensation, surface growth, and coagulation, and external ones such as diffusion, convection and thermophoresis [110]. The PBE was first described from Schmoluchowski's discrete coagulation equation [111],

$$
\frac{\partial N_{i}}{\partial t}=\frac{1}{2} \sum_{j=1}^{i-1} \beta_{j, i-j} N_{i} N_{i-j}-\sum_{j=1}^{\infty} \beta_{i, j} N_{i} N_{j},
$$

where $N_{i}$ is the number density of particles of size class $i$ and $\beta_{i, j}$ is the collision frequency factor between particles of size classes $i$ and $j$. The Eq. (12) first term represents the formation of new particles with size $i$ due to the collision of smaller particles, the second one corresponds to the loss of particles with size $i$ due to their collision with particles of other size classes.

Schmoluchowski's continue coagulation equation was extended later on by Muller in the form of an integro-differential equation [112]. Accordingly, soot formation processes such as surface growth and oxidation are considered as continuous changes in the soot particle volume, because they come from both subtraction and addition of small atoms. This is why the continuous form of the coagulation equation is best suited to derive the PBE general expression. The PBE general form including surface processes, nucleation and coagulation is expressed as [2],

$$
\begin{aligned}
\frac{\partial n}{\partial t}+\frac{\partial(G n)}{\partial t}=B & \delta\left(v_{i}-v_{0}\right)+\frac{1}{2} \int_{0}^{v_{i}} \beta\left(v_{j}, v_{i}-v_{j}\right) n\left(v_{j}\right) n\left(v_{i}-v_{j}\right) d v_{j} \\
& -\int_{0}^{\infty} \beta\left(v_{i}, v_{j}\right) n\left(v_{i}\right) n\left(v_{j}\right) d v_{j}
\end{aligned}
$$

where $n \equiv n(v, t)$ is the particle number density indicating the number of particles with volume between $v$ and $v+\delta v$ per unit of particle volume at time $t, G$ is the rate of change of particle volume due to surface processes, and $B$ is the nucleation rate. The coagulation kernels $\beta$ are defined in turn according to the particle regime determined by the Knudsen number $K n=2 \lambda / d_{i}$, relating the gas mean free path $\lambda$ and the particle diameter $d_{i}$. When $K n \gg 1$ the particles are 
considered as belonging to the free molecular regime, whereas for $\mathrm{Kn} \ll 1$ the particles are within the continuous regime. In addition, when $0.1 \leq K n \leq 10$ the particles are accounted for as being in the transition regime [13]. The coagulation kernels in the three referred particle regimens are given by [13], [113],

$$
\begin{aligned}
& \beta_{i, j}^{f}=C_{a}\left(\frac{3}{4 \pi}\right)^{\frac{1}{6}}\left(\frac{6 k_{B} T}{\rho_{s}}\right)^{\frac{1}{2}}\left(\frac{1}{v_{i}}-\frac{1}{v_{j}}\right)^{\frac{1}{2}}\left(v_{i}^{\frac{1}{3}}+v_{j}^{\frac{1}{3}}\right)^{2}, \\
& \beta_{i, j}^{c}=\frac{2 k_{B} T}{3 \mu}\left(\frac{C_{i}}{v_{i}^{\frac{1}{3}}}+\frac{C_{i}}{v_{j}^{\frac{1}{3}}}\right)\left(v_{i}^{\frac{1}{3}}+v_{j}^{\frac{1}{3}}\right), \\
& \beta_{i, j}^{t}=\frac{\beta_{i, j}^{f} \beta_{i, j}^{c}}{\beta_{i, j}^{f}+\beta_{i, j}^{c}} .
\end{aligned}
$$

In Eqs. (14)-(16) the superscripts $f, c$ and $t$ relate to the free molecular, continuum and transition regimes, respectively. $k_{B}$ is in turn the Boltzmann constant, $\mu$ is the gas viscosity, $\rho_{s}$ is the soot density, $C_{i}=1+1257 \mathrm{Kn}$ is the Cunningham slip correction factor, and $C_{a}$ is the van der Waals enhancement factor [73].

Notice that soot particles coagulate until they reach a point where the soot aggregation phenomenon becomes important and soot chains start to be formed. This soot chains formation process is set to begin when soot particles reach sizes of about 25-30 nm [13]. The aggregation process needs to be added then to the PBE equation. This is done by accounting for the diameter of the fractal aggregates $d_{c}=d_{\text {prim }} N_{p}{ }^{1 / D_{f}}$, which is defined in terms of the primary particles diameter $d_{\text {prim }}$, the number of primary particles per aggregate $N_{p}$, and the fractal characteristic dimension $D_{f}$ [73]. Accordingly, in order to take into account for soot aggregation, the coagulation kernel is modified for the free molecular and continuous regimes as shown in Eqs. (17) and (18), whereas the transient regime related kernel (Eq. (16)) remains dependent on both kernels [114],

$$
\begin{gathered}
\beta_{i, j}^{f}=C_{a} \sqrt{\frac{\pi k_{B} T}{\rho_{s}\left(v_{i}+v_{j}\right)}}\left(d_{c, i}+d_{c, j}\right)^{2}, \\
\beta_{i, j}^{c}=\frac{2 k_{B} T}{3 \mu}\left(\frac{C_{i}}{d_{c, i}}+\frac{C_{i}}{d_{c, j}}\right)\left(d_{c, i}+d_{c, j}\right) .
\end{gathered}
$$

Owing to the fact that the PBE is an integro-differential equation solving it is challenging. Getting a direct numerical solution of the PBE is indeed relatively expensive, even with current technology. Over the years different approaches have been proposed to obtain an approximate solution to this equation. These approaches can be classified as, (i) methods of moments [12], [14], [92], [115], (ii) sectionals methods [15], [105], [116], and (iii) Monte Carlo methods [17], [18]. 


\subsubsection{Methods of moments}

The different variants of the method of moments (MOM) rely on the description of the PSDF through few low order statistical moments, avoiding in this way the direct resolution of the PBE equation and saving on computational cost. Notice here that on one hand by knowing all the referred moments it is possible to know the PSDF itself. On the other hand, if the PSDF shape is known, it can be described by two moments only, for instance, soot concentration number and soot volume fraction [8]. In the method of moments-based approaches the governing equation for the $i$ rth-order moment is given by,

$$
\mathrm{m}_{k}=\int_{0}^{\infty} v^{k} n(v) d v
$$

where $k$ stands for the order of the statistical moment. The zero-order moment $\mathrm{m}_{0}=\int_{0}^{\infty} n(v) d v$ represents then the total number of particles and the first-order one $\mathrm{m}_{1}=\int_{0}^{\infty} v n(v) d v$ the total particle volume [20]. The moment transport equations are derived by multiplying Eq. (13) with $v^{k}$ and subsequently integrating over phase space to obtain [2],

$$
\begin{aligned}
\int_{0}^{\infty} v^{k} \frac{\partial}{\partial t} n(v) d v & =-\int_{0}^{\infty} v^{k} \frac{\partial}{\partial t}(G(v) n(v)) d v \\
& +\int_{0}^{\infty} v^{k} B \delta\left(v-v_{0}\right) d v \\
& +\int_{0}^{\infty} v^{k} \frac{1}{2} \int_{0}^{v_{i}} \beta\left(v_{j}, v_{i}-v_{j}\right) n\left(v_{j}\right) n\left(v_{i}-v_{j}\right) d v_{j} d v_{i} \\
& -\int_{0}^{\infty} v^{k} \int_{0}^{\infty} \beta\left(v_{i}, v_{j}\right) n\left(v_{i}\right) n\left(v_{j}\right) d v_{j} d v_{i}
\end{aligned}
$$

It is worth noticing that Eq. (20) can be expressed in terms of other coordinates or integration variables such as mass of soot or soot surface area [117]. Soot volume is accounted for here as the integration variable because it allows getting a more suitable description of some soot formation related processes such as coagulation and aggregation. The moment transport equations usually include terms related to higher order statistical moments that are unavailable, so these terms represent unclosed ones. Although these higher order moments lack of physical interpretation they are necessary to improve predictions accuracy. Different techniques have developed over the years for dealing with the referred closure problem and each of them is associated with a particular formulation of the method of moments. The first method of moments for instance was proposed by Hulburt and Katz [118] based on a series expansion of the particle number density function.

Two of the most commonly used methods of moments in soot formation studies are the method of moments with interpolative closure (MOMIC) [119] and the Gaussian quadrature method of moments (QMOM) [120]. These two methods have evolved through the years originating the different variants of the method of moments currently available. MOMIC was initially proposed by Frenklach and Harris [119] and since then it has been extensively improved 
as described in several research works [12], [13], [28]. As any other method of moments, MOMIC solves only a given set of moments of the PSDF transported by the PBE. More specifically, the open terms depending on fractional moments of negative and positive order that appear in the associated PSDF moment transport equations are handled using Lagrange interpolating polynomials. That is a Lagrangian interpolation function based on low order moments is used to describe the unknown moments, as follows,

$$
\log M_{k}=L_{k}\left(\log M_{o}, \log M_{1}, \ldots, \log M_{n}\right)=\sum_{i=0}^{n} \log M i \prod_{\substack{j=0 \\ j \neq i}}^{n} \frac{k-j}{i-j}
$$

where $L_{k}$ represents the Lagrange logarithmic interpolation function. Advantages usually associated with MOMIC include simplicity, computational efficiency, numerical robustness and straightforward implementation into 3D computational fluid dynamics (CFD) tools [121]. Notice however that this model cannot describe the bimodality of the PSDF [14]. MOMIC has been applied in different soot related studies from laminar flames [9], [13], [122] to turbulent ones [123], [124].

Another approach for computing PSDF moments originally proposed by McGraw [120] is the QMOM based model. This particular MOM model solves the closure problem arising in the moment transport equations using an n-point Gaussian quadrature approximation, and in particular by transforming the associated PDF into a finite number of delta equations. Mathematically, a Gaussian quadrature computes any integral using an approximation of the form [125],

$$
\int_{\Omega} f(x) d x=\sum_{i=1}^{N x} w_{i} f\left(x_{i}\right)
$$

where $w_{i}$ represent the weights, $x_{i}$ the abscissas and $N x$ is the number of weights or abscissas. In the QMOM both abscissas and weights are determined by moment inversion algorithms in terms of low order moments so the $k$-th order moments are computed from,

$$
\int_{0}^{\infty} v^{k} n(v) d v \approx \sum_{i=1}^{n} w_{i} v_{i}^{k}
$$

QMOM was initially developed for modeling just soot growth processes [120]. Later on however it was applied to other soot related processes such as coagulation and breakage [126], [127]. QMOM can be implemented relatively easily in CFD packages and it is useful when solving monovariate problems. Due to its inherent limitations however it is applicable to monovariate distributions only. The main drawbacks of this method relate to the fact that it requires the inversion of the matrix generated by the abscissas and weights and a subsequent integration of the transported moments. Likewise, it is possible that the system of equations resulting from the matrix is ill conditioned, which means that the solution exists but it is difficult 
to find it. In order to solve these limitations, Marchisio and Fox [115] developed the direct quadrature method of moments (DQMOM) model. This model involves transporting the Gaussian quadrature weights and abscissas instead of the PDF moments so it can be applied to multivariate PSDF. Compared to the QMOM, the DQMOM based model is advantageous since it avoids the intermediate step of matrix inversion, which makes easier its implementation in CFD tools. DQMOM presents problems of moments conservation however due to the nonlinear relationship between quadrature abscissas and PDF moments. The conditional quadrature method of moments (CQMOM) [128], a robust multivariate method employing conditional function theory to solve the PSDF, constitutes one of the more recent developments in this category of soot models. CQMOM requires in particular the transport of a slightly larger number of moments (mixed moments). The extended quadrature method of moments (EQMOM) [129] uses in turn a kernel density function (KDF) to approximate the PSDF. Applications of this family of methods of moments are discussed in several past research efforts, including those by Blanquart and Pitsch, [42], Salenbauch et al. [92] and Wick et al. [130]. It is worth noticing here as well the hybrid method of moments (HMOM) [14], which combines both MOMIC and DQMOM concepts. In the HMOM indeed, MOMIC concepts are used to interpolate fractional moments for fractal aggregates, whereas DQMOM ones are used to compute moments for spherical particles. Different studies have been also carried out by Mueller and co-workers using this soot formation model [67], [80].

\subsubsection{Sectional methods}

These detailed soot formation models describe the PSDF evolution using of a discrete number of sections, which result from the partitioning of all soot particles in a given number of sets according to one of their internal coordinates (e.g., soot particles volume). In these models the soot formation processes are evaluated for each section rather than for each individual soot particle. When using sectional methods for soot predictions different issues arise as well. Coagulation for instance involves solving the entire particles domain because when two particles coagulate the resulting one may belong to a section that differs to the one where the coagulation process occurred, requiring in this way a large number of operations. Furthermore, the surface growth term may involve sharp fronts due to the first order hyperbolic form of the PBE [2]. In order to solve these issues, several variants of the sectional methods have been proposed over the years. Following Rigopoulos [131] thus, two categories of sectional methods based models exist. The first category refers to the so-called methods of classes, which involves transporting a PSDF resembling a piecewise constant function, where the whole range of particle volumes is divided into discrete points $v_{i}$, each point having a constant PSDF value. In the second category of sectional methods, in each section accounted for, the PSDF is approximated as a function of $v$ and varies then across each section. 
In the first group of sectional methods the $v$-defined spaces are based on a geometric grid. One of the early research works associated with this category of soot models was focused on aggregation problems and the grid utilized there followed a progression of the form $v_{i+1} / v_{i}=2$ [132]. An initial issue present in these particular methods related to their incapability of conserving first lower moments that are useful to describe important physical quantities. Hounslow et al. [133] solved later on this problem by conserving the soot total mass and number particles (i.e., first and second order moments) and coupling soot aggregation with surface growth. The grids employed in these works followed the geometric progression $v_{i+1} / v_{i}=2^{q}$, where $q$ is an integer number. Kumar and Ramkrishna [134], [135] developed a more flexible approach with no limitations on the grid and capable of conserving any two chosen moments. This particular method is often called pivot technique. Park and Rogak [136] employed this last method in order to discretize the coagulation term and to study soot formation in laminar flames.

In the other group of sectional methods, also called fine element methods (FEM), over the years different continuous functions describing the PSDF in each bin or section have been utilized. These functions include splines ones [137], collocation and Galerkin methods [138], and collocation with linear trial functions [139]. Netzell et al. [16] developed a particular sectional method that solves for the soot volume fraction instead of the soot number density. This method, which is not directly derived from FEM based schemes, was used in different soot studies from laminar flames [140], [141] to turbulent ones [16], [59]. Other sectional methods have been also derived using finite volume methods (FVM) based approaches [142], [143]. In order to deal with the issues associated with soot surface growth different approaches have been proposed over the years, including moving grids [144], high resolution fixed grids [136] and adaptive grids [145].

In the work by Netzell et al. [16] in particular, the volume domain is divided in $N_{s e c}$ sections. The section volumes are in the range defined by volume of the smallest particle $v_{M I N}$ and the volume of the largest particle $v_{M A X}$. Here the particle minimum volume is equal to the carbonequivalent volume of the number of carbon atoms of two soot precursors and two acetylene molecules. The carbon-equivalent volume for two atoms of carbon is given by,

$$
v_{C 2}=\frac{2 M_{C}}{N_{A} \rho_{s}}
$$

where $M_{C}$ is the molar mass of carbon, $N_{A}$ is the Avogadro number, and $\rho_{S}$ represents soot density. In the referred work each section $i$ is defined by the limits $v_{i-1}$ and $v_{i}$ in such a way that the highest volume particle of section $i$ is the smallest particle of section $i+1$. The discretization of the PSDF is given then by,

$$
v_{i, \max }=v_{M I N} \cdot\left(\frac{v_{M A X}}{v_{M I N}}\right)^{\frac{i}{i_{\max }}}
$$


In turbulent reactive flows, in order to describe the soot evolution, a transport equation for the soot mass fraction $Y_{s, i}$ is solved for each section [59],

$$
\frac{\partial\left(\rho Y_{s, i}\right)}{\partial t}+\nabla \cdot\left(\rho \bar{v} Y_{s, i}\right)=-\nabla \cdot\left(\rho v_{T} Y_{s, i}\right)+\nabla \cdot\left(\rho D_{s, i} \nabla Y_{s, i}\right)+\rho_{s} \dot{Q}_{s, i}
$$

where $\rho$ is the gas phase density, $\bar{v}$ is the gas velocity, $D_{s, i}$ is the turbulent diffusion coefficient, $v_{T}$ is the thermophoretic velocity, $\rho_{S}$ is the soot density and $\dot{Q}_{S, i}$ is the production rate of soot mass fraction (i.e., source terms, $\left.\dot{Q}_{s, i}=\left(\rho / \rho_{s}\right) Y_{s, i}\right)$. Eq. (26) source term includes all the processes involved in soot formation as follows,

$$
\dot{Q}_{s, i}=\dot{Q}_{n u c, i}+\dot{Q}_{c o n d, i}+\dot{Q}_{s g, i}+\dot{Q}_{o x, i}+\dot{Q}_{c o a g, i}
$$

where $\dot{Q}_{n u c, i}, \dot{Q}_{c o n d, i}, \dot{Q}_{s g, i}, \dot{Q}_{o x, i}, \dot{Q}_{\text {coag }, i}$ are the source terms due to soot nucleation, condensation, surface growth, oxidation and coagulation, respectively. Netzell et al. [16] accounted for a constant soot volume fraction density $\dot{q}_{s, i}=\frac{\dot{Q}_{s, i}}{v_{i, \text { max }}-v_{i, \min }}$ for each bin or section and showed that this hypothesis has a small influence on the PSDF solution.

Finally, since both soot volume fraction density $\dot{q}_{s, i}$ and soot density $\rho_{s}$ are considered here as constant, the soot volume fraction $f_{v}$ and the particle number density $N$ can be evaluated as,

$$
\begin{aligned}
& f_{v}=\int_{0}^{\infty} q(v) d v, \\
& N=\int_{0}^{\infty} n(v) d v .
\end{aligned}
$$

\subsubsection{Monte Carlo methods}

Monte Carlo modeling approaches are stochastic methods that compute PBE approximate solutions by both accounting for a smaller number of stochastic particles that represent the total soot particle population and subjecting the referred stochastic particles to random events. These events include several particle dynamics related processes such as those associated with soot formation and fluid flow. By following this approach, the complete statistical characteristics of the soot particle population may be described. The main advantage of Monte Carlo methods is that they provide all the PSDF moments. This improvement however implies a relatively high computational cost, which depending on the level of description of the turbulent reacting flow, could be prohibitive. In order to reduce the referred computational cost and broaden the applicability of Monte Carlo methods, different numerical techniques have been proposed over the years. These approaches include constant-volume or constant-number [146], [147] ones, timeor event-driven [148], [149] approaches, majorant kernels and binary trees based techniques [150], and stochastic weighted methods [148], [151]. Although these numerical techniques have been able to reduce the associated computational costs, Monte Carlo methods have been mainly applied so far in one dimensional laminar flames [18], [152]. They are yet to meet with challenge 
of unsteady three dimensional simulations of combustion processes of industrial interest [153]. Because this review work focuses on turbulent reacting flows, Monte Carlo methods will not be further discussed here.

\section{Soot models comparative results}

The results obtained from the usage of a plethora of soot models, which have been validated utilizing experimental data, have been compared in several past works. Both laminar and turbulent flames have been considered in such comparisons. In this work however, a particular emphasis is put on those results obtained for turbulent diffusion flames. Some of the main comparative analyses of soot models performed during the last years are therefore reviewed in this section. This review process aims to emphasize the differences in the results obtained when using different soot models. Notice that the illustrations containing soot models' comparative results are reproduced here as they were published. Therefore, the nomenclature utilized in the original works has been kept in the figures discussed in this section. When required thus a proper correspondence between the original nomenclature and that one used in this work is highlighted in figure captions.

Figure 1 shows some of the main results from the work by Muller and Pitsch [14], where the hybrid method of moments (HMOM) is introduced and validated using the experimental measurements carried out by Pels Leusden and Peters [154]. As described in Section 4, this hybrid model combines the ease of implementation of the MOMIC with the description of soot particle size distribution bimodality presented by the DQMOM. In the referred work, HMOM, MOMIC and DQMOM were implemented within the Flamemaster code [155], whereas Monte Carlo independently modeled soot dynamics taking the Flamemaster outputs (temperature, species mass fractions, PAH dimerization rate). These soot models were used for predicting soot formation in an acetylene counterflow non-premixed laminar flame, accounting for nucleation, coagulation, condensation, surface growth, oxidation and a pure aggregation collision model. No radiation model was utilized there. In Figure 1 top plots, $t$ represents the residence time as measured from the oxidizer stream to the stagnation plane. The kinetic mechanism utilized was the one developed by Blanquart et al. [156], which considers PAHs ranging from benzene to coronene (up to six aromatic rings). MOMIC was based on six moments, HMOM used the same six moments and the weight of the first delta function, whereas DQMOM was enhanced with two delta functions. 


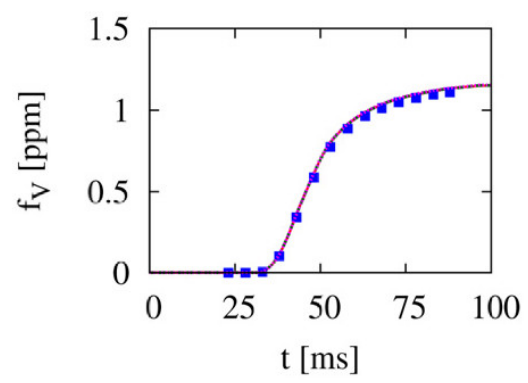

Volume fraction

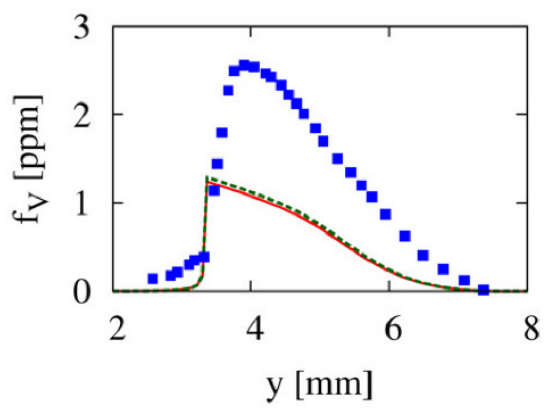

Volume fraction

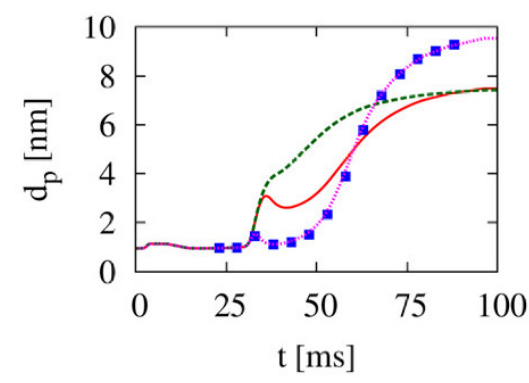

Primary particle diameter

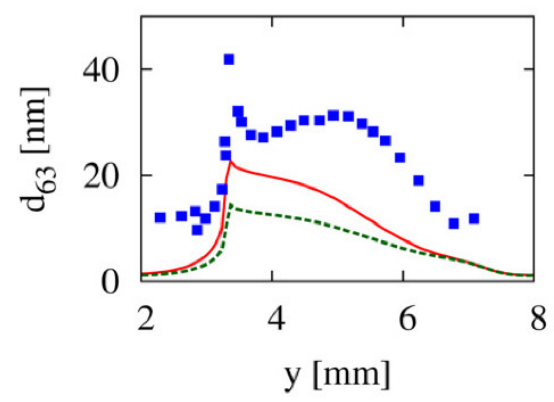

Scattering/extinction diameter

Figure 1 Mean soot properties in an acetylene counterflow diffusion flame. Top plots correspond to soot models' comparisons. Solid lines correspond to HMOM, dashed lines to MOMIC, dotted lines to DQMOM and symbols are Monte Carlo based results. Bottom plots correspond to HMOM comparisons with experimental data. Solid lines correspond to HMOM with multi regime collision model, dashed lines are HMOM with a pure aggregation model and symbols are experimental measurements [14].

From the results shown in Figure 1 top left plot it may be seen that all soot models predict identical soot volume fraction. This occurs because the mass of soot results from the same nucleation and condensation processes, which are governed by the chemical mechanism and the nucleation model utilized. Furthermore, it may be observed from Figure 1 top right plot that DQMOM in particular is able to accurately describe the main characteristics of the soot particle population, approaching to the Monte Carlo method with 104 particles. In addition, it is apparent that MOMIC cannot capture the local decrease in soot particle diameter since this model does not account for small particles. HMOM in turn captures the decrease in particle diameter up to $35 \mathrm{~ms}$ of residence time but to a lesser extent than using DQMOM or the Monte Carlo method. HMOM was also compared with experimental data of soot volume fraction and particle diameter (Figure 1 bottom plots) and the corresponding results were underpredicted by a factor of two. Since the chemical mechanism and the nucleation model employed are responsible for most of the soot mass formed, this HMOM outcome could not be related to the particle model utilized only.

Chong et al. [157] carried out several numerical simulations of turbulent sooting flames in a representative aircraft combustor based on the study by Geigle et al. [158]. These simulations were performed using two kinetic mechanisms, the NBP mechanism [43] and the KAM 1.0 one [159]. Both of these mechanisms include detailed PAH chemistry but the first one considers PAH 
up to four aromatic rings only, whereas the second one accounts for up to seven aromatic rings. Each mechanism coupled to three different soot models, a semi-empirical model based on acetylene soot inception, HMOM and CQMOM. Six different sets of results were thus obtained. In order to model turbulent combustion, LES was used in conjunction with a radiation flamelet/progress variable (RFPV) approach, which included a heat loss parameter accounting for radiation effects from both soot and gas species [67]. The moment source terms considered included nucleation and PAH condensation, particle coagulation (both coalescence and aggregation), surface growth by acetylene addition, oxidation and fragmentation by oxidizing species. Radial distributions of soot volume fraction and soot number density at a given axial location $(45 \mathrm{~mm})$ are illustrated in Figure 2.
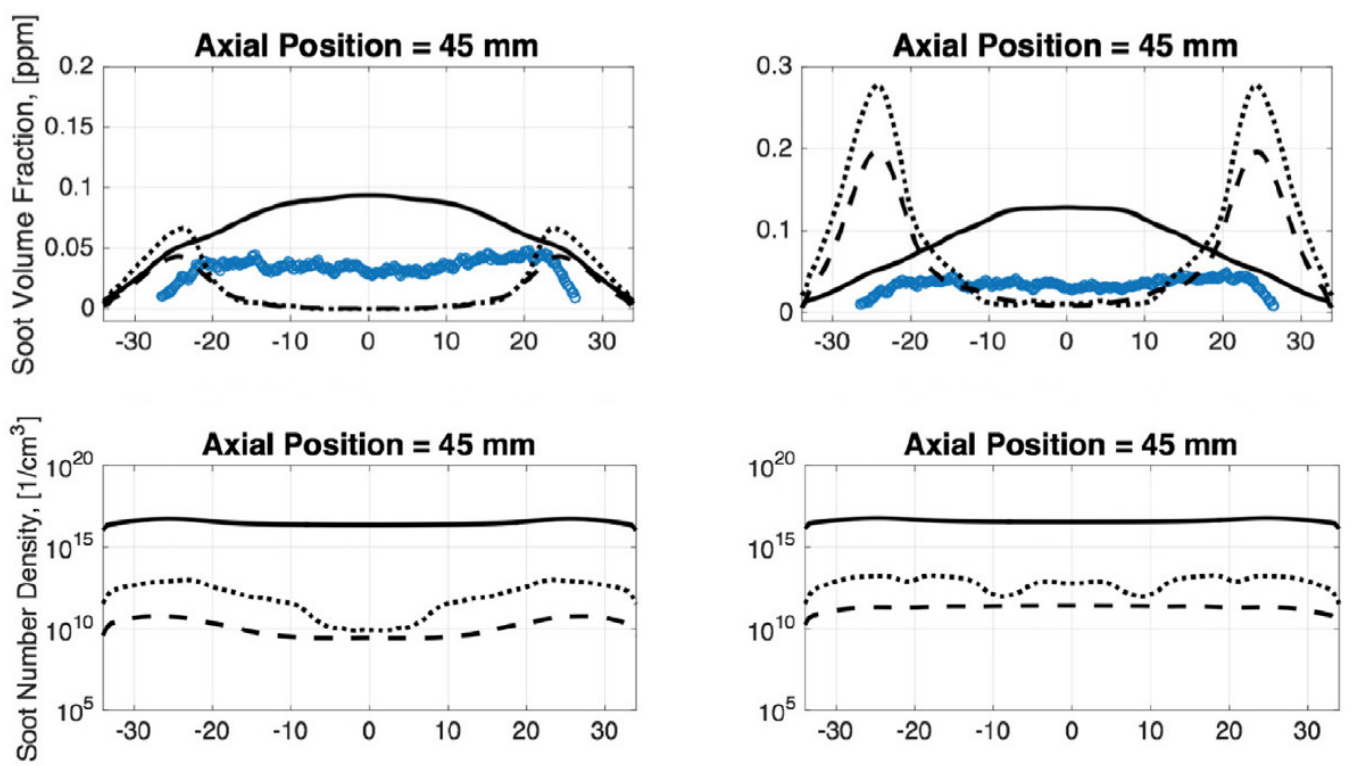

Figure 2 Comparisons of soot volume fraction (top) and soot number density (bottom) for two different kinetic mechanisms, NBP (left) and KAM 1.0 (right). Solid lines correspond to a semi empirical model, dotted lines to HMOM, dashed lines to CQMOM, whereas blue scatter represents experimental data [157].

From Figure 2 it may be noticed that, in terms of soot volume fraction, none of the soot models utilized led to results close to the measurements. Compared to the NBP mechanism indeed, the KAM 1.0 resulted in soot volume fraction values four times higher. Chong et al. [157] argue that this discrepancy comes from both the base chemistry and the PAH growth pathways, which are different in each of these two kinetic mechanisms. Regarding the studied soot models, HMOM and CQMON led to similar qualitative soot volume fraction results for both mechanisms, with HMOM values up to two times larger than the CQMOM ones. In the referred work it is indicated that, since HMOM predicts a faster coagulation rate, thus reducing the surface area, this difference is due to the coagulation process. Compared to the other two soot models analyzed, the semi-empirical one resulted in turn in considerably higher values of soot number density, which is consistent with the corresponding soot volume fraction. This indicates that the acetylene-based 
inception model employed in the semi empirical model produces a higher inception rate than PAH-based inception models.

Rodrigues et al. [59] used a soot sectional model for predicting soot formation in a turbulent ethylene/air jet diffusion flame [160]. The soot production rate accounted for nucleation, condensation, surface growth, oxidation and coagulation. The obtained results were compared with previously obtained experimental data [161]. KM2 [41] was used as kinetic mechanism, which accounts for 202 chemical species, 1351 reactions and considers PAH up to coronene. LES was employed as turbulence model and turbulent-chemistry interactions were modeled using an extended flamelet/progress variable (FPV) model developed by Ihme and Pitsch [162]. Figure 3 shows the soot volume fraction profile obtained using the soot sectional method accounted for, which included 25 sections. It can be seen from this figure that the peak of soot volume fraction is overpredicted by the model by a factor of 2 . When compared to experiments as well, the numerical predictions indicate a narrower soot volume fraction distribution. Rodrigues et al. [59] point out that previous studies carried out on the same flame [67], underestimated the soot volume fraction. So it is concluded there that the obtained prediction accuracy is comparable to the state of the art soot predictions carried out elsewhere [163].

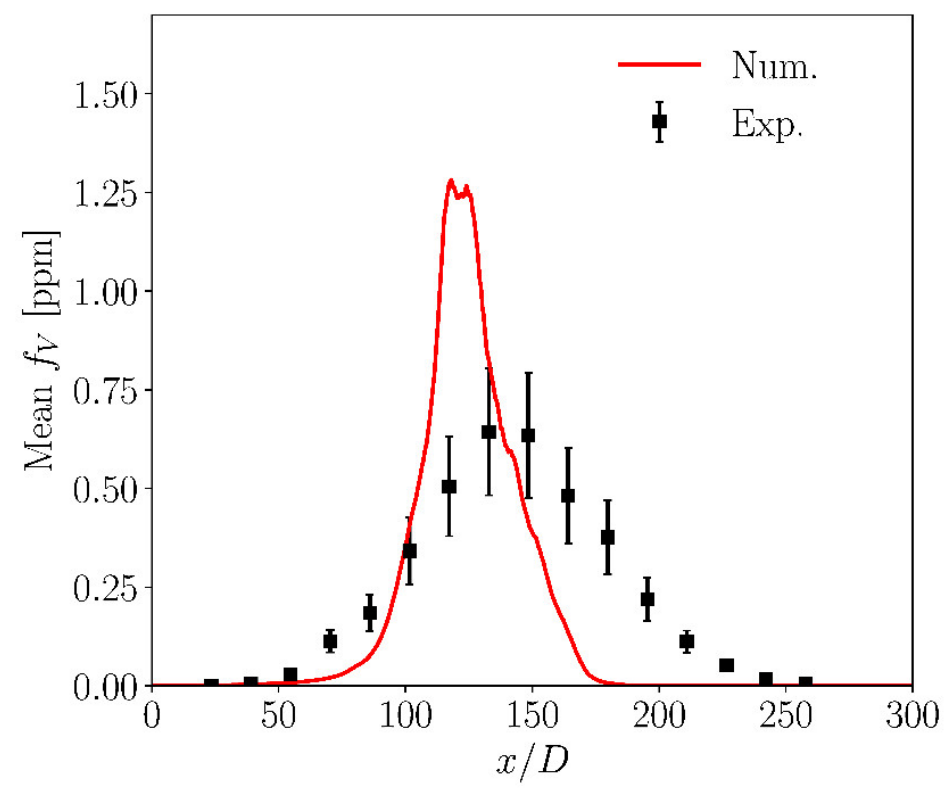

Figure 3 Soot volume fraction mean axial profiles predicted using a soot sectional method [59]. Experimental data from reference [161].

In the work by Yang and Muller [10], the basis of a new multi-moment sectional method (MMSM) is described. This model is a combination of the moment with the sectional methods, in which multiple statistical moments are solved within each section. MMSM can be reduced to a classical method of moments by taking only one section. Similarly, it can be transformed into a sectional method by considering a single moment for each section. In order to illustrate the 
capabilities of MMSM, a study in an ethylene laminar premixed flame was carried out. The associated results indicate that MMSM features a higher convergence rate when compared to the classical sectional method. Both of these methods were implemented within FlameMaster [155] in order to study a burner stabilized laminar premixed flat flame [164]. The source terms accounted for included nucleation, coagulation, growth and destruction. The chemical kinetic mechanism employed was the NBP developed by Naraynaswamy et al. [43], which include detailed PAH chemistry and accounts for up to seven aromatic rings. No radiation model was accounted for.

Figure 4 shows a set of results from the work by Yang and Muller [10] with and without accounting for soot particles smaller than $2.5 \mathrm{~nm}$. These relatively small particles have been removed from one of the simulated cases because in the experimental results [164] used for comparison purposes they were not measured. The numbers shown in Figure 4 plot legends correspond to the number of variables that must be solved under each model. When using both the sectional method and the MMSM one, an over prediction of the soot number density was observed associated with the corresponding overprediction of the soot nucleation rate. Furthermore, in terms of soot volume fraction and soot number density, both methods led to values that lie within the experimental uncertainty range. The new MMSM model achieves however a faster convergence with fewer variables to be solved, which implies a smaller number of transport equations and consequently a lower computational cost.

It is worth noticing that the results obtained using the soot formation models discussed in this section are very sensitive to the gas phase kinetic mechanisms employed. This aspect is particularly emphasized in Figure 2, where different kinetic mechanisms (NBP on left plots and KAM 1.0 on right ones) lead to different rates of soot volume fraction. Depending on the kinetic mechanism utilized then, the soot predictions accuracy may be compromised. Accounting for kinetic mechanisms featuring hundreds of chemical species and thousands of chemical reactions could in principle lead to more accurate soot predictions. By doing so however, the computational burden will significantly increase making the turbulent combustion numerical simulations prohibitive. Likewise, in order to carry out a fair comparison among the existing soot formation modeling approaches it is essential that these models be analyzed under the same conditions. These conditions include reacting flow configuration, turbulence, combustion and radiation modeling, as well turbulence-chemistry-radiation interactions. 

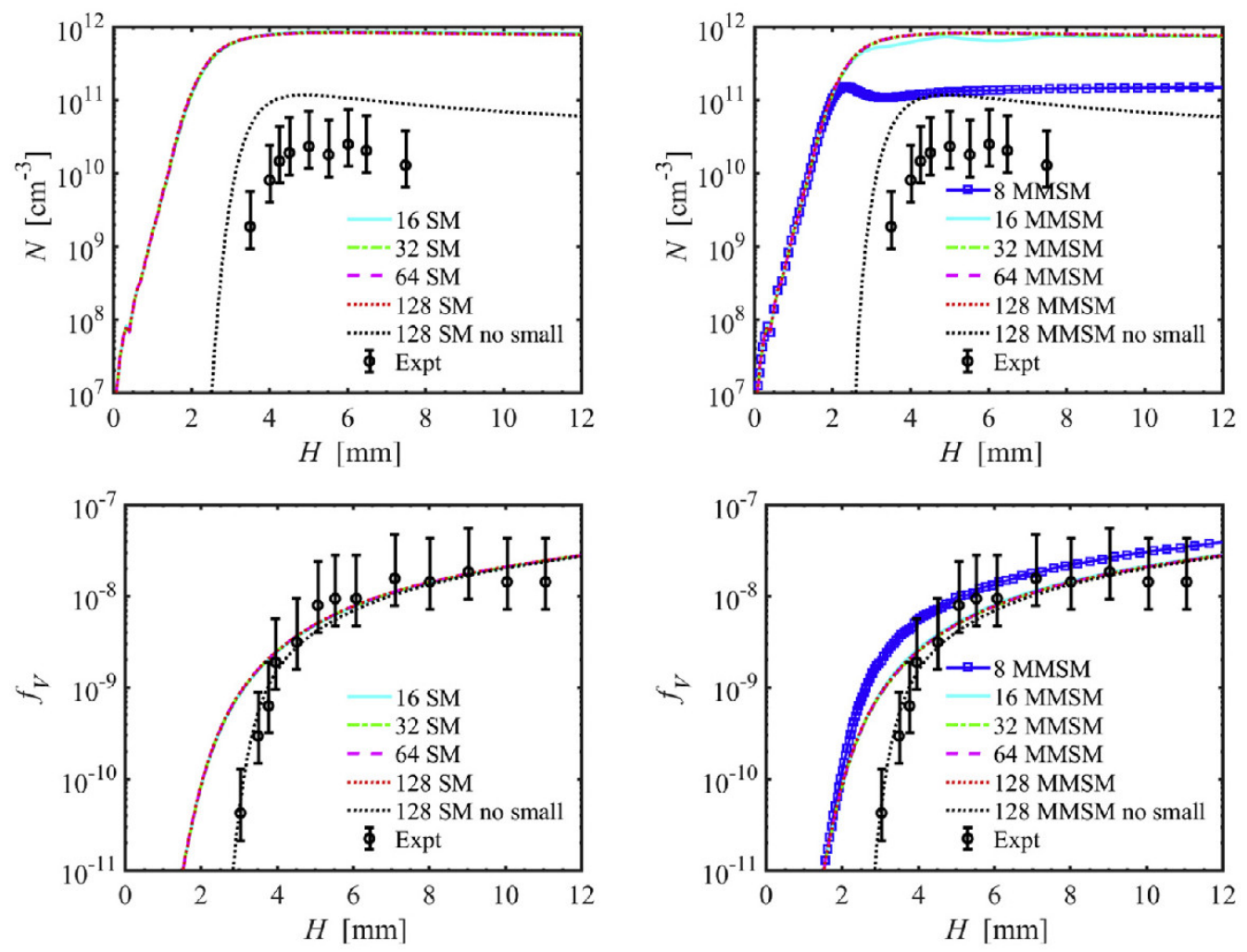

Figure 4 Mean soot quantities through the flame for both the sectional method (left) and the MMSM one (right). Lines represent numerical results and symbols correspond to experimental data with uncertainties [10].

Currently, the most accurate soot modeling approach is the Monte Carlo one. Due to its relatively high computational cost however, its implementation for three-dimensional turbulent reacting flows is not affordable yet. For soot predictions in turbulent combustion processes then, the most accurate and affordable method is the sectional one. Depending on the number of sections employed in this model however, its computational cost can be considerably high as well. Regarding the methods of moments, because it captures the bimodality of the soot particle size distribution, the most accurate one is the DQMOM, followed by the HMOM. Even though this last soot model is not as accurate as the DQMOM, it strongly reduces the computational cost making it one of the most widely used methods for soot predictions in turbulent flames. Thus, the simplest and cheapest soot formation models are those based on the assumption of a monodisperse soot size distribution. These models do not properly represent however the actual soot formation phenomena. Prediction accuracy and computational cost represent therefore two critical aspects to be accounted for when modeling soot formation in actual combustion systems.

\section{Soot models prospects}

In recent years soot modeling in laminar non-premixed flames has seen crucial developments regarding detailed chemical kinetics, soot particle growth and size distribution. Even so coagulation/agglomeration processes related models are still subject of debate, and soot 
nucleation models fail to incorporate the various physico-chemical phenomena that are known to arise in combustion processes. In particular, the transition from several ringed PAH to nascent soot is a matter of ongoing research. This fundamental knowledge, which still lacks in laminar flames, is paramount to the understanding of soot formation in turbulent flames. The development of this knowledge requires carefully designed experiments to which diverse analytical measurement techniques would be applied to quantify trace species concentrations for various fuel/oxidizer/diluent mixtures.

Concerning the coagulation and agglomeration processes, different approaches models have been proposed recently, such as the one combining the sectional method with the method of moments. In this hybrid model, due to the reduction in the number of variables to be calculated, the accuracy level of a classical sectional method is obtained at a lower computational cost. The referred hybrid method has been originally developed for laminar flow. It is expected however that this method can be extended in future for turbulent flames since in terms of computational cost it represents an interesting alternative to the sectional one. Additionally, a recently work by Bounaiche [153] proposes a new soot model combining the sectional method with the Monte Carlo one. Turbulent reacting flows related applications are foreseen as well for this recently proposed soot model.

Turbulent combustion models have traditionally relied on laminar flames as their basic building blocks. This is justified by the high activation energy, exothermic chemical reactions that control the associated irreversible combustion heat release processes, which include a relatively few pathways involving species concentrations of the order of hundreds of ppm. The PAH reaction pathways are however thermodynamically reversible and involve a yet unknown number of controlling steps relating high molecular weight species that exist in trace amounts. This poses the question of the adequacy of using classical chemistry reduction techniques to bring the gas phase kinetics description to an amenable complexity or size. In particular, the classical flamelet- or manifold-like techniques reducing the physico-chemical system to a few controlling scalars should not be expected to yield meaningful results for soot precursor species. Nevertheless, models that would find use in engineering applications must involve a handful of gas-phase scalars only. These models should be derived by combining physico-chemical based approaches and optimization techniques seeking to describe the various time and length scales involved.

Given the importance to energy balance in sooting flames, thermal radiation transport should be dealt with proper models. Fortunately, the radiation related databases required to use narrow or wide band models for gas phase species have matured in the past few years, as there is a consensus that Monte Carlo methods should provide the most consistent basis for future models, due to the combined flexibility and accuracy. Accounting for soot thermal radiation requires 
however a model for the complex index of refraction, which is known to be a function of both the radiation wavelength, and the particle maturity, oxidation state and morphology. Describing this extremely complex functional dependency is subject of ongoing research, whose outcome will influence the turbulence sooting flames models.

Modeling efforts are nurtured by experimental data. Usually, turbulent non-premixed flames experimental studies have allowed characterizing soot volume fraction, global emissions, radiant intensity and, seldom, temperature, OH-PLIF and PAH-PLIF. Soot particle size distributions however, which are crucial to the development of accurate models for laminar flames, have not yet been measured. It should be stressed that, when compared to non-sooting flames, soot loading introduces significant measurement challenges. For instance, in order to measure flow velocity fields, most of the velocimetry techniques rely on the detection of laser-illuminated seeding particles. This detection is marred however with interference from the intense broadband natural soot emission, which may not be properly dealt with even when high laser powers are combined with fast shutters. Such a broadband emission may also hamper the detection of chemical species that could otherwise be measured via laser induced fluorescence, such as PAH. Nevertheless, performing the referred measurements is a mandatory prerequisite to the development of predictive models for a range of turbulent flow conditions.

\section{Conclusions}

In this work the state-of-the-art of the main soot modeling approaches used in turbulent diffusion flames were reviewed. More specifically, the main soot formation mechanisms were initially described. Because of the strong coupling between chemistry, turbulence and soot formation, a general overview about combustion and radiation models was provided next. The most successful modeling approaches currently available for predicting soot in turbulent combustion processes were then reviewed. Both advantages and disadvantages of the referred soot models were discussed, along with comparisons of results obtained using these soot models. Regarding the recently addressed soot formation mechanisms, two main pathways for soot formation were particularly emphasized. The well-stablished pathway involving the HACA mechanism leading to PAH formation, and an alternative one involving reactions over a pool of radicals, resulting in the formation of aromatics that either are linked by aliphatic or feature aliphatic branches. It is worth noticing that those soot formation pathways may occur concurrently, and their relative importance may depend on specific reacting flow conditions. Some key species to account for in chemical kinetic mechanisms employed in soot modeling processes include five-membered ring molecules and the referred aliphatic radicals. Further research is therefore required to get a better understanding of soot formation kinetics, and more specifically about soot inception and the PAH and OAC clustering processes. Soot oxidation and 
fragmentation reducing soot mass fraction are crucial in soot formation so they must be also considered when modeling soot.

Detailed discussions about the main soot modeling approaches currently available for predicting soot formation in turbulent flames, ranging from the simplest semi-empirical models to the more complex detailed ones, were provided. It is worth noticing first that using semiempirical models involves a relatively low computational cost. The fact that these models do not describe soot particles morphology represents however a significant shortcoming. Monte Carlo methods are yet to be applied for predicting soot formation in turbulent flames because of their relatively high computational cost. This is why the most widely used soot modeling approaches in these flames are those based on both the method of moments and the sectional method. In these two categories of soot modeling approaches there are several flavors featuring different soot prediction accuracy and computational cost. In terms of accuracy, the sectional method is usually considered as better than the method of moments. Some limitations of the sectional method however relate to the fact that this model cannot be extended to multivariate situations and its computational cost is relatively high. The method of moments-based models features a lower computational cost because in order to describe the PSDF the transport a few statistical moments is needed only. Different variants of the method of moments have been proposed over the years in order both to solve the closure problems arising when using this modeling approach and to characterize properly the PSDF bimodality. Overall, based on the literature reviewed, it is concluded that there is yet a long path to be followed before understanding first and having then a soot model able to properly describe the formation of this critical pollutant for a variety of situations of industrial interest.

\section{Acknowledgements}

This work has been supported by CONCYTEC-FONDECYT (Peru), Contract No. 415-20192019-FONDECYT, "Identification of soot precursors in turbulent combustion processes through numerical modeling to reduce the impact of soot on both health and environment". During this work Luís Fernando Figueira da Silva was on leave from the Institut Pprime (CNRS - Centre National de la Recherche Scientifique, France). The authors also gratefully acknowledge the support provided by Brazil's Conselho Nacional de Desenvolvimento Cientifico e Tecnologico, CNPq, under the Research Grants No. 306069/2015-6 and 403904/2016-1.

\section{References}

[1] I. M. Kennedy, 'Models of soot formation and oxidation', Prog. Energy Combust. Sci., vol. 23, no. 2, pp. 95-132, 1997, doi: 10.1016/S0360-1285(97)00007-5.

[2] S. Rigopoulos, 'Modelling of Soot Aerosol Dynamics in Turbulent Flow', Flow, Turbul. 
Combust., vol. 103, no. 3, pp. 565-604, 2019, doi: 10.1007/s10494-019-00054-8.

[3] T. Bourdrel, M. A. Bind, Y. Béjot, O. Morel, and J. F. Argacha, 'Effets cardiovasculaires de la pollution de l'air', Arch. Cardiovasc. Dis., vol. 110, no. 11, pp. 634-642, 2017, doi: 10.1016/j.acvd.2017.05.003.

[4] W. M. Baird, L. A. Hooven, and B. Mahadevan, 'Carcinogenic polycyclic aromatic hydrocarbon-DNA adducts and mechanism of action', Environ. Mol. Mutagen., vol. 45, no. 2-3, pp. 106-114, 2005, doi: 10.1002/em.20095.

[5] H. Wang, 'Formation of nascent soot and other condensed-phase materials in flames', Proc. Combust. Inst., vol. 33, no. 1, pp. 41-67, 2011, doi: 10.1016/j.proci.2010.09.009.

[6] I. Glassman and R. A. Yetter, Combustion, 4th ed. Academic Press, 2008.

[7] X. Mercier, O. Carrivain, C. Irimiea, A. Faccinetto, and E. Therssen, 'Dimers of polycyclic aromatic hydrocarbons: The missing pieces in the soot formation process', Phys. Chem. Chem. Phys., vol. 21, no. 16, pp. 8285-8294, 2019, doi: 10.1039/c9cp00394k.

[8] A. D'Anna and M. Sirignano, 'Detailed kinetic mechanisms of PAH and soot formation', Comput. Aided Chem. Eng., vol. 45, pp. 647-672, 2019, doi: 10.1016/B978-0-444-640871.00012-7.

[9] J. Appel, H. Bockhorn, and M. Frenklach, 'Kinetic modeling of soot formation with detailed chemistry and physics: Laminar premixed flames of C2 hydrocarbons', Combust. Flame, vol. 121, no. 1-2, pp. 122-136, 2000, doi: 10.1016/S0010-2180(99)00135-2.

[10] S. Yang and M. E. Mueller, 'A Multi-Moment Sectional Method (MMSM) for tracking the soot Number Density Function', Proc. Combust. Inst., vol. 37, no. 1, pp. 1041-1048, 2019, doi: 10.1016/j.proci.2018.06.107.

[11] L. Gallen, A. Felden, E. Riber, and B. Cuenot, 'Lagrangian tracking of soot particles in les of gas turbines', Proc. Combust. Inst., vol. 37, no. 4, pp. 5429-5436, 2019, doi: 10.1016/j.proci.2018.06.013.

[12] M. Frenklach, 'Method of moments with interpolative closure', Chem. Eng. Sci., vol. 57, no. 12, pp. 2229-2239, 2002, doi: 10.1016/S0009-2509(02)00113-6.

[13] A. Kazakov and M. Frenklach, 'Dynamic modeling of soot particle coagulation and aggregation: Implementation with the method of moments and application to highpressure laminar premixed flames', Combust. Flame, vol. 114, no. 3-4, pp. 484-501, 1998, doi: 10.1016/S0010-2180(97)00322-2.

[14] M. E. Mueller, G. Blanquart, and H. Pitsch, 'Hybrid Method of Moments for modeling soot formation and growth', Combust. Flame, vol. 156, no. 6, pp. 1143-1155, 2009, doi: 
10.1016/j.combustflame.2009.01.025.

[15] F. Gelbard, Y. Tambour, and J. H. Seinfeld, 'Sectional representations for simulating aerosol dynamics', J. Colloid Interface Sci., vol. 76, no. 2, pp. 541-556, 1980, doi: 10.1016/0021-9797(80)90394-X.

[16] K. Netzell, H. Lehtiniemi, and F. Mauss, 'Calculating the soot particle size distribution function in turbulent diffusion flames using a sectional method', Proc. Combust. Inst., vol. 31 I, no. 1, pp. 667-674, 2007, doi: 10.1016/j.proci.2006.08.081.

[17] H. Zhao, C. Zheng, and M. Xu, 'Multi-Monte Carlo method for coagulation and condensation/evaporation in dispersed systems', J. Colloid Interface Sci., vol. 286, no. 1, pp. 195-208, 2005, doi: 10.1016/j.jcis.2004.12.037.

[18] M. Balthasar and M. Kraft, 'A stochastic approach to calculate the particle size distribution function of soot particles in laminar premixed flames', Combust. Flame, vol. 133, no. 3, pp. 289-298, 2003, doi: 10.1016/S0010-2180(03)00003-8.

[19] S. Salenbauch, M. Sirignano, M. Pollack, A. D'Anna, and C. Hasse, 'Detailed modeling of soot particle formation and comparison to optical diagnostics and size distribution measurements in premixed flames using a method of moments', Fuel, vol. 222, no. February, pp. 287-293, 2018, doi: 10.1016/j.fuel.2018.02.148.

[20] V. Raman and R. O. Fox, 'Modeling of Fine-Particle Formation in Turbulent Flames', Annu. Rev. Fluid Mech., vol. 48, no. 1, pp. 159-190, 2016, doi: 10.1146/annurev-fluid122414-034306.

[21] Y. Wang and S. H. Chung, 'Soot formation in laminar counterflow flames', Prog. Energy Combust. Sci., vol. 74, pp. 152-238, 2019, doi: 10.1016/j.pecs.2019.05.003.

[22] M. Frenklach, 'Reaction mechanism of soot formation in flames', Phys. Chem. Chem. Phys., vol. 4, no. 11, pp. 2028-2037, May 2002, doi: 10.1039/b110045a.

[23] H. Richter and J. B. Howard, Formation of polycyclic aromatic hydrocarbons and their growth to soot-a review of chemical reaction pathways, vol. 26, no. 4. 2000.

[24] A. D’Anna, Kinetics of Soot Formation. Elsevier Inc., 2015.

[25] S. Sinha, R. K. Rahman, and A. Raj, 'On the role of resonantly stabilized radicals in polycyclic aromatic hydrocarbon (PAH) formation: Pyrene and fluoranthene formation from benzyl-indenyl addition', Phys. Chem. Chem. Phys., vol. 19, no. 29, pp. 1926219278, 2017, doi: 10.1039/c7cp02539d.

[26] N. M. Marinov, M. J. Castaldi, S. M. Melius, and W. Tsang, 'Aromatic and Polycyclic Aromatic Hydrocarbon Formation in a Premixed Propane Flame', Combust. Sci. Technol., 
vol. 128, no. 1-6, pp. 295-342, 1997, doi: 10.1080/00102209708935714.

[27] M. Frenklach and H. Wang, 'Detailed modeling of soot particle nucleation and growth', Symp. Combust., vol. 23, no. 1, pp. 1559-1566, 1991, doi: 10.1016/S00820784(06)80426-1.

[28] M. Frenklach and H. Wang, Detailed mechanism and modeling of soot particle formation, no. 59. 1994.

[29] K. O. Johansson et al., 'Soot precursor formation and limitations of the stabilomer grid', Proc. Combust. Inst., vol. 35, no. 2, pp. 1819-1826, 2015, doi: 10.1016/j.proci.2014.05.033.

[30] M. Commodo et al., 'On the early stages of soot formation: Molecular structure elucidation by high-resolution atomic force microscopy', Combust. Flame, vol. 205, pp. 154-164, 2019, doi: 10.1016/j.combustflame.2019.03.042.

[31] K. O. Johansson, M. P. Head-Gordon, P. E. Schrader, K. R. Wilson, and H. A. Michelsen, 'Resonance-stabilized hydrocarbon-radical chain reactions may explain soot inception and growth', Science (80-. )., vol. 361, no. 6406, pp. 997-1000, 2018, doi: 10.1126/science.aat3417.

[32] S. H. Chung and A. Violi, 'Peri-condensed aromatics with aliphatic chains as key intermediates for the nucleation of aromatic hydrocarbons', Proc. Combust. Inst., vol. 33, no. 1, pp. 693-700, 2011, doi: 10.1016/j.proci.2010.06.038.

[33] P. Elvati and A. Violi, 'Thermodynamics of poly-aromatic hydrocarbon clustering and the effects of substituted aliphatic chains', Proc. Combust. Inst., vol. 34, no. 1, pp. 1837-1843, 2013, doi: 10.1016/j.proci.2012.07.030.

[34] Z. A. Mansurov, 'Soot formation in combustion processes', Combust. Explos. Shock Waves, vol. 41, no. 6, pp. 727-744, 2005.

[35] M. E. Mueller, G. Blanquart, and H. Pitsch, 'Modeling the oxidation-induced fragmentation of soot aggregates in laminar flames', Proc. Combust. Inst., vol. 33, no. 1, pp. 667-674, 2011, doi: 10.1016/j.proci.2010.06.036.

[36] F. Battin-Leclerc, J. M. Simmie, E. Blurock, D. D. Chemical, and K. Models, Cleaner Combustion. 2013.

[37] N. A. Slavinskaya and P. Frank, 'A modelling study of aromatic soot precursors formation in laminar methane and ethene flames', Combust. Flame, vol. 156, no. 9, pp. 1705-1722, 2009, doi: 10.1016/j.combustflame.2009.04.013.

[38] N. Slavinskaya et al., 'A modelling study of acetylene oxidation and pyrolysis', Combust. 
Flame, vol. 210, pp. 25-42, 2019, doi: 10.1016/j.combustflame.2019.08.024.

[39] W. Pejpichestakul et al., 'Examination of a soot model in premixed laminar flames at fuelrich conditions', Proc. Combust. Inst., vol. 37, no. 1, pp. 1013-1021, 2019, doi: 10.1016/j.proci.2018.06.104.

[40] A. Kéromnès et al., 'An experimental and detailed chemical kinetic modeling study of hydrogen and syngas mixture oxidation at elevated pressures', Combust. Flame, vol. 160, no. 6, pp. 995-1011, 2013, doi: 10.1016/j.combustflame.2013.01.001.

[41] Y. Wang, A. Raj, and S. H. Chung, 'A PAH growth mechanism and synergistic effect on PAH formation in counterflow diffusion flames', Combust. Flame, vol. 160, no. 9, pp. 1667-1676, 2013, doi: 10.1016/j.combustflame.2013.03.013.

[42] G. Blanquart and H. Pitsch, 'Analyzing the effects of temperature on soot formation with a joint volume-surface-hydrogen model', Combust. Flame, vol. 156, no. 8, pp. 1614-1626, 2009, doi: 10.1016/j.combustflame.2009.04.010.

[43] K. Narayanaswamy, G. Blanquart, and H. Pitsch, 'A consistent chemical mechanism for oxidation of substituted aromatic species', Combust. Flame, vol. 157, no. 10, pp. 18791898, 2010, doi: 10.1016/j.combustflame.2010.07.009.

[44] A. D'Anna, 'Detailed kinetic modeling of particulate formation in rich premixed flames of ethylene', Energy and Fuels, vol. 22, no. 3, pp. 1610-1619, 2008, doi: 10.1021/ef700641u.

[45] A. D'Anna and J. H. Kent, 'Modeling of particulate carbon and species formation in coflowing diffusion flames of ethylene', Combust. Flame, vol. 144, no. 1-2, pp. 249-260, 2006, doi: 10.1016/j.combustflame.2005.07.011.

[46] F. E. \& C. K. L. Hai Wang, Xiaoqing You, Ameya V. Joshi, Scott G. Davis, Alexander Laskin, 'USC Mech Version II. High-Temperature Combustion Reaction Model of H2/CO/C1-C4 Compounds.', 2007. .

[47] H. Richter, S. Granata, W. H. Green, and J. B. Howard, 'Detailed modeling of PAH and soot formation in a laminar premixed benzene/oxygen/argon low-pressure flame', Proc. Combust. Inst., vol. 30, no. 1, pp. 1397-1405, 2005, doi: 10.1016/j.proci.2004.08.088.

[48] A. Ergut et al., 'PAH formation in one-dimensional premixed fuel-rich atmospheric pressure ethylbenzene and ethyl alcohol flames', Combust. Flame, vol. 144, no. 4, pp. 757-772, 2006, doi: 10.1016/j.combustflame.2005.07.019.

[49] A. A. Konnov, A. Mohammad, V. R. Kishore, N. Il Kim, C. Prathap, and S. Kumar, 'A comprehensive review of measurements and data analysis of laminar burning velocities 
for various fuel+air mixtures', Prog. Energy Combust. Sci., vol. 68, pp. 197-267, Sep. 2018, doi: 10.1016/j.pecs.2018.05.003.

[50] A. J. Aspden, M. S. Day, and J. B. Bell, 'Turbulence-chemistry interaction in lean premixed hydrogen combustion', Proc. Combust. Inst., vol. 35, no. 2, pp. 1321-1329, 2015, doi: 10.1016/j.proci.2014.08.012.

[51] H. Carlsson, R. Yu, and X. S. Bai, 'Direct numerical simulation of lean premixed CH4/air and H2/air flames at high Karlovitz numbers', Int. J. Hydrogen Energy, vol. 39, no. 35, pp. 20216-20232, 2014, doi: 10.1016/j.ijhydene.2014.09.173.

[52] M. S. Day, X. Gao, and J. B. Bell, 'Properties of lean turbulent methane-air flames with significant hydrogen addition', Proc. Combust. Inst., vol. 33, no. 1, pp. 1601-1608, 2011, doi: 10.1016/j.proci.2010.05.099.

[53] S. Lapointe, B. Savard, and G. Blanquart, 'Differential diffusion effects, distributed burning, and local extinctions in high Karlovitz premixed flames', Combust. Flame, vol. 162, no. 9, pp. 3341-3355, 2015, doi: 10.1016/j.combustflame.2015.06.001.

[54] D. Dasgupta, W. Sun, M. Day, and T. Lieuwen, 'Effect of turbulence-chemistry interactions on chemical pathways for turbulent hydrogen-air premixed flames', Combust. Flame, vol. 176, pp. 191-201, 2017, doi: 10.1016/j.combustflame.2016.09.029.

[55] D. Dasgupta, W. Sun, M. Day, A. J. Aspden, and T. Lieuwen, 'Analysis of chemical pathways and flame structure for n-dodecane/air turbulent premixed flames', Combust. Flame, vol. 207, pp. 36-50, 2019, doi: 10.1016/j.combustflame.2019.05.026.

[56] W. Han, V. Raman, M. E. Mueller, and Z. Chen, 'Effects of combustion models on soot formation and evolution in turbulent nonpremixed flames', Proc. Combust. Inst., vol. 37, no. 1, pp. 985-992, 2019, doi: 10.1016/j.proci.2018.06.096.

[57] M. E. Mueller and V. Raman, 'Effects of turbulent combustion modeling errors on soot evolution in a turbulent nonpremixed jet flame', Combust. Flame, vol. 161, no. 7, pp. 1842-1848, 2014, doi: 10.1016/j.combustflame.2013.12.020.

[58] S. Yang, J. K. Lew, and M. E. Mueller, 'Large Eddy Simulation of soot evolution in turbulent reacting flows: Presumed subfilter PDF model for soot-turbulence-chemistry interactions', Combust. Flame, vol. 209, pp. 200-213, 2019, doi: 10.1016/j.combustflame.2019.07.040.

[59] P. Rodrigues, B. Franzelli, R. Vicquelin, O. Gicquel, and N. Darabiha, 'Coupling an LES approach and a soot sectional model for the study of sooting turbulent non-premixed flames', Combust. Flame, vol. 190, pp. 477-499, 2018, doi: 10.1016/j.combustflame.2017.12.009. 
[60] H. Pitsch, 'Large-Eddy Simulation of Turbulent Combustion', Annu. Rev. Fluid Mech., vol. 38, no. 1, pp. 453-482, 2006, doi: 10.1146/annurev.fluid.38.050304.092133.

[61] N. Peters, 'Laminar diffusion flamelet models in non-premixed turbulent combustion', Prog. Energy Combust. Sci., vol. 10, no. 3, pp. 319-339, 1984, doi: 10.1016/03601285(84)90114-X.

[62] A. Jain and Y. Xuan, 'Effects of large aromatic precursors on soot formation in turbulent non-premixed sooting jet flames', Combust. Theory Model., vol. 23, no. 3, pp. 439-466, 2019, doi: 10.1080/13647830.2018.1549751.

[63] H. Pitsch, M. Chen, and N. Peters, 'Unsteady flamelet modeling of turbulent hydrogen-air diffusion flames', Symp. Combust., vol. 27, pp. 1057-1064, 1998.

[64] C. D. Pierce and P. Moin, 'Progress-variable approach for large-eddy simulation of nonpremixed turbulent combustion', J. Fluid Mech., vol. 504, no. 504, pp. 73-97, 2004, doi: $10.1017 / \mathrm{S} 0022112004008213$

[65] M. Ihme, C. M. Cha, and H. Pitsch, 'Prediction of local extinction and re-ignition effects in non-premixed turbulent combustion using a flamelet/progress variable approach', Proc. Combust. Inst., vol. 30, no. 1, pp. 793-800, 2005, doi: 10.1016/j.proci.2004.08.260.

[66] M. Thme and Y. C. See, 'Prediction of autoignition in a lifted methane/air flame using an unsteady flamelet/progress variable model', Combust. Flame, vol. 157, no. 10, pp. 18501862, 2010, doi: 10.1016/j.combustflame.2010.07.015.

[67] M. E. Mueller and H. Pitsch, 'LES model for sooting turbulent nonpremixed flames', Combust. Flame, vol. 159, no. 6, pp. 2166-2180, 2012, doi: 10.1016/j.combustflame.2012.02.001.

[68] D. C. Haworth, 'Progress in probability density function methods for turbulent reacting flows', Prog. Energy Combust. Sci., vol. 36, no. 2, pp. 168-259, 2010, doi: 10.1016/j.pecs.2009.09.003.

[69] S. B. Pope, 'PDF methods for turbulent reactive flows', Prog. Energy Combust. Sci., vol. 11, no. 2, pp. 119-192, 1985, doi: 10.1016/0360-1285(85)90002-4.

[70] C. Celis and L. F. Figueira Da Silva, 'Lagrangian mixing models for turbulent combustion: Review and prospects', Flow, Turbul. Combust., vol. 94, no. 3, pp. 643-689, 2015, doi: 10.1007/s10494-015-9597-1.

[71] S. L. Yilmaz, N. Ansari, P. H. Pisciuneri, M. B. Nik, C. C. Otis, and P. Givi, 'Applied filtered density function', J. Appl. Fluid Mech., vol. 6, no. 3, pp. 311-320, 2013, doi: 10.36884/jafm.6.03.19578. 
[72] M. A. Chishty, M. Bolla, E. R. Hawkes, Y. Pei, and S. Kook, 'Soot formation modelling for n-dodecane sprays using the transported PDF model', Combust. Flame, vol. 192, pp. 101-119, 2018, doi: 10.1016/j.combustflame.2018.01.028.

[73] M. A. Schiener and R. P. Lindstedt, 'Joint-scalar transported PDF modelling of soot in a turbulent non-premixed natural gas flame', Combust. Theory Model., vol. 22, no. 6, pp. 1134-1175, 2018, doi: 10.1080/13647830.2018.1472391.

[74] M. A. Schiener and R. P. Lindstedt, 'Transported probability density function based modelling of soot particle size distributions in non-premixed turbulent jet flames', Proc. Combust. Inst., vol. 37, no. 1, pp. 1049-1056, 2019, doi: 10.1016/j.proci.2018.06.088.

[75] M. F. Modest and D. C. Haworth, Radiative Heat Transfer in Turbulent Combustion Systems: Theory and Applications. 2016.

[76] M. F. Modest, Radiative Heat Transfer, 3rd Ed., no. January 2010. Academic Press, 2013.

[77] P. Wang, F. Fan, and Q. Li, 'Accuracy evaluation of the gray gas radiation model in CFD simulation', Case Stud. Therm. Eng., vol. 3, pp. 51-58, 2014, doi: 10.1016/j.csite.2014.03.003.

[78] H. H. C. and S. A. F., 'Radiative Transfer', McGraw-Hill, New York, US, pp. 795-797, 1967.

[79] P. Donde, V. Raman, M. E. Mueller, and H. Pitsch, 'LES/PDF based modeling of sootturbulence interactions in turbulent flames', Proc. Combust. Inst., vol. 34, no. 1, pp. 11831192, 2013, doi: 10.1016/j.proci.2012.07.055.

[80] M. E. Mueller et al., 'Experimental and computational study of soot evolution in a turbulent nonpremixed bluff body ethylene flame', Combust. Flame, vol. 160, no. 7, pp. 1298-1309, 2013, doi: 10.1016/j.combustflame.2013.02.010.

[81] A. C. Nunno and M. E. Mueller, 'Manifold assumptions in modeling radiation heat losses in turbulent nonpremixed combustion', Proc. Combust. Inst., vol. 37, no. 2, pp. 22232230, 2019, doi: 10.1016/j.proci.2018.06.232.

[82] F. R. Centeno, F. Cassol, H. A. Vielmo, F. H. R. França, and C. V. Da Silva, 'Comparison of different WSGG correlations in the computation of thermal radiation in a $2 \mathrm{D}$ axisymmetric turbulent non-premixed methane-air flame', J. Brazilian Soc. Mech. Sci. Eng., vol. 35, no. 4, pp. 419-430, 2013, doi: 10.1007/s40430-013-0040-z.

[83] A. G. Clements et al., 'LES and RANS of air and oxy-coal combustion in a pilot-scale facility: Predictions of radiative heat transfer', Fuel, vol. 151, pp. 146-155, 2015, doi: 10.1016/j.fuel.2015.01.089. 
[84] F. R. Centeno, R. Brittes, F. H. R. França, and C. V. Da Silva, 'Application of the WSGG model for the calculation of gas-soot radiation in a turbulent non-premixed methane-air flame inside a cylindrical combustion chamber', Int. J. Heat Mass Transf., vol. 93, pp. 742-753, 2016, doi: 10.1016/j.ijheatmasstransfer.2015.09.054.

[85] C. V. da Silva, D. L. Deon, F. R. Centeno, F. H. R. França, and F. M. Pereira, 'Assessment of combustion models for numerical simulations of a turbulent non-premixed natural gas flame inside a cylindrical chamber', Combust. Sci. Technol., vol. 190, no. 9, pp. 15281556, 2018, doi: 10.1080/00102202.2018.1456430.

[86] A. K. Agarwal, A. Pandey, S. Chaudhuri, and S. Sen, Modeling and Simulation of Turbulent Combustion. Singapore: Springer Singapore, 2018.

[87] L. Wang, M. F. Modest, D. C. Haworth, and S. R. Turns, 'Modelling nongrey gas-phase and soot radiation in luminous turbulent nonpremixed jet flames', Combust. Theory Model., vol. 9, no. 3, pp. 479-498, 2005, doi: 10.1080/13647830500194834.

[88] D. A. Lysenko, I. S. Ertesvåg, and K. E. Rian, 'Numerical simulation of non-premixed turbulent combustion using the eddy dissipation concept and comparing with the steady laminar flamelet model', Flow, Turbul. Combust., vol. 93, no. 4, pp. 577-605, 2014, doi: 10.1007/s10494-014-9551-7.

[89] M. A. Chishty, M. Bolla, E. R. Hawkes, Y. Pei, and S. Kook, 'The effect of radiation heat transfer under ECN Spray A conditions', Proc. Aust. Combust. Symp., pp. 1-4, 2015.

[90] M. C. Paul, 'Performance of the various Sn approximations of DOM in a 3D combustion chamber', J. Heat Transfer, vol. 130, no. 7, pp. 1-7, 2008, doi: 10.1115/1.2897924.

[91] D. Poitou, J. Amaya, M. El Hafi, and B. Cuénot, 'Analysis of the interaction between turbulent combustion and thermal radiation using unsteady coupled LES/DOM simulations', Combust. Flame, vol. 159, no. 4, pp. 1605-1618, 2012, doi: 10.1016/j.combustflame.2011.12.016.

[92] S. Salenbauch, A. Cuoci, A. Frassoldati, C. Saggese, T. Faravelli, and C. Hasse, 'Modeling soot formation in premixed flames using an Extended Conditional Quadrature Method of Moments', Combust. Flame, vol. 162, no. 6, pp. 2529-2543, 2015, doi: 10.1016/j.combustflame.2015.03.002.

[93] D. Aubagnac-Karkar, J. B. Michel, O. Colin, P. E. Vervisch-Kljakic, and N. Darabiha, 'Sectional soot model coupled to tabulated chemistry for Diesel RANS simulations', Combust. Flame, vol. 162, no. 8, pp. 3081-3099, 2015, doi: 10.1016/j.combustflame.2015.03.005.

[94] A. Attili, F. Bisetti, M. E. Mueller, and H. Pitsch, 'Effects of non-unity Lewis number of 
gas-phase species in turbulent nonpremixed sooting flames', Combust. Flame, vol. 166, pp. 192-202, 2016, doi: 10.1016/j.combustflame.2016.01.018.

[95] M. Lucchesi, A. Abdelgadir, A. Attili, and F. Bisetti, 'Simulation and analysis of the soot particle size distribution in a turbulent nonpremixed flame', Combust. Flame, vol. 178, pp. 35-45, 2017, doi: 10.1016/j.combustflame.2017.01.002.

[96] E. M. Orbegoso, L. F. Figueira Da Silva, and R. Serfaty, 'Comparative study of thermal radiation properties models in turbulent non-premixed sooting combustion', Numer. Heat Transf. Part A Appl., vol. 69, no. 2, pp. 166-179, 2016, doi: 10.1080/10407782.2015.1052318.

[97] A. Jerez, J. J. Cruz Villanueva, L. F. Figueira da Silva, R. Demarco, and A. Fuentes, 'Measurements and modeling of PAH soot precursors in coflow ethylene/air laminar diffusion flames', Fuel, vol. 236, no. September 2018, pp. 452-460, 2019, doi: 10.1016/j.fuel.2018.09.047.

[98] H. Sheikhani, H. Ajam, and M. Ghazikhani, 'A review of flame radiation research from the perspective of factors affecting the flame radiation, measurement and modeling', Eur. Phys. J. Plus, vol. 135, no. 4, 2020, doi: 10.1140/epjp/s13360-020-00350-7.

[99] B. M. Reddy, A. De, and R. Yadav, 'Numerical investigation of soot formation in turbulent diffusion flame with strong turbulence-chemistry interaction', J. Therm. Sci. Eng. Appl., vol. 8, no. 1, pp. 1-11, 2016, doi: 10.1115/1.4030694.

[100] S. J. Brookes and J. B. Moss, 'Measurements of soot production and thermal radiation from confined turbulent jet diffusion flames of methane', Combust. Flame, vol. 116, no. 1-2, pp. 49-61, 1999, doi: 10.1016/S0010-2180(98)00027-3.

[101] I. M. Aksit and J. B. Moss, 'A hybrid scalar model for sooting turbulent flames', Combust. Flame, vol. 145, no. 1-2, pp. 231-244, 2006, doi: 10.1016/j.combustflame.2005.10.010.

[102] M. D. Smooke, C. S. McEnally, L. D. Pfefferle, R. J. Hall, and M. B. Colket, 'Computational and experimental study of soot formation in a coflow, laminar diffusion flame', Combust. Flame, vol. 117, no. 1-2, pp. 117-139, 1999, doi: 10.1016/S00102180(98)00096-0.

[103] M. Oubal et al., 'A new semi-empirical model for the oxidation of polycyclic aromatic hydrocarbon (PAHs) molecules physisorbed on soot. II. application to the reaction PAH + OH for a series of large PAH molecules', Comput. Theor. Chem., vol. 965, no. 2-3, pp. 259-267, 2011, doi: 10.1016/j.comptc.2010.10.048.

[104] K. M. Leung, R. P. Lindstedt, and W. P. Jones, 'A simplified reaction mechanism for soot formation in nonpremixed flames', Combust. Flame, vol. 87, no. 3-4, pp. 289-305, 1991, 
doi: 10.1016/0010-2180(91)90114-Q.

[105] J. S. Bhatt and R. P. Lindstedt, 'Analysis of the impact of agglomeration and surface chemistry models on soot formation and oxidation', Proc. Combust. Inst., vol. 32 I, no. 1, pp. 713-720, 2009, doi: 10.1016/j.proci.2008.06.201.

[106] K. M. Pang, H. K. Ng, and S. Gan, 'Simulation of temporal and spatial soot evolution in an automotive diesel engine using the Moss-Brookes soot model', Energy Convers. Manag., vol. 58, no. x, pp. 171-184, 2012, doi: 10.1016/j.enconman.2012.01.015.

[107] M. Reddy, A. De, and R. Yadav, 'Effect of precursors and radiation on soot formation in turbulent diffusion flame', Fuel, vol. 148, pp. 58-72, 2015, doi: 10.1016/j.fuel.2015.01.080.

[108] M. R. Busupally and A. De, 'Numerical modeling of Soot formation in a turbulent C2H4/air diffusion flame', Int. J. Spray Combust. Dyn., vol. 8, no. 2, pp. 67-85, 2016, doi: $10.1177 / 1756827716638814$.

[109] A. Snegirev, E. Markus, E. Kuznetsov, J. Harris, and T. Wu, 'On soot and radiation modeling in buoyant turbulent diffusion flames', Heat Mass Transf. und Stoffuebertragung, vol. 54, no. 8, pp. 2275-2293, 2018, doi: 10.1007/s00231-017-2198$\mathrm{x}$.

[110] S. K. Friedlander, Smoke, Dust, and Haze: Fundamentals of Aerosol Dynamics (2nd ed.). 2000.

[111] M. . Smoluchowski, 'Mathematical theory of the kinetics of coagulation of colloidal systems', Z. Phys. Chem. 92, pp. 129-168, 1917.

[112] H. Müller, 'Zur allgemeinen Theorie ser raschen Koagulation', Kolloidchem. Beihefte, vol. 27, no. 6-12, pp. 223-250, 1928, doi: 10.1007/bf02558510.

[113] S. E. Pratsinis, 'Simultaneous nucleation, condensation, and coagulation in aerosol reactors', J. Colloid Interface Sci., vol. 124, no. 2, pp. 416-427, 1988, doi: 10.1016/00219797(88)90180-4.

[114] S. Vemury and S. E. Pratsinis, 'Self-preserving size distributions of agglomerates', $J$. Aerosol Sci., vol. 26, no. 2, pp. 175-185, 1995, doi: 10.1016/0021-8502(94)00103-6.

[115] D. L. Marchisio and R. O. Fox, 'Solution of population balance equations using the direct quadrature method of moments', J. Aerosol Sci., vol. 36, no. 1, pp. 43-73, 2005, doi: 10.1016/j.jaerosci.2004.07.009.

[116] S. H. Park, S. N. Rogak, W. K. Bushe, J. Z. Wen, and M. J. Thomson, 'An aerosol model to predict size and structure of soot particles', Combust. Theory Model., vol. 9, no. 3, pp. 
499-513, 2005, doi: 10.1080/13647830500195005.

[117] M. Yu and J. Lin, 'Hybrid method of moments with interpolation closure-Taylor-series expansion method of moments scheme for solving the Smoluchowski coagulation equation', Appl. Math. Model., vol. 52, pp. 94-106, 2017, doi: 10.1016/j.apm.2017.07.052.

[118] H. M. Hulburt and S. Katz, 'Some problems in particle technology', Chem. Eng. Sci., vol. 19, no. 8, pp. 555-574, 1964, doi: 10.1016/0009-2509(64)85047-8.

[119] M. Frenklach and S. J. Harris, 'Aerosol dynamics modeling using the method of moments', J. Colloid Interface Sci., vol. 118, no. 1, pp. 252-261, 1987, doi: 10.1016/00219797(87)90454-1.

[120] R. McGraw, 'Description of aerosol dynamics by the quadrature method of moments', Aerosol Sci. Technol., vol. 27, no. 2, pp. 255-265, 1997, doi: $10.1080 / 02786829708965471$.

[121] A. Wick, M. Frenklach, and H. Pitsch, 'Systematic assessment of the Method of Moments with Interpolative Closure and guidelines for its application to soot particle dynamics in laminar and turbulent flames', Combust. Flame, 2020, doi: 10.1016/j.combustflame.2020.01.007.

[122] M. E. Mueller, G. Blanquart, and H. Pitsch, 'A joint volume-surface model of soot aggregation with the method of moments', Proc. Combust. Inst., vol. 32 I, no. 1, pp. 785792, 2009, doi: 10.1016/j.proci.2008.06.207.

[123] R. P. Lindstedt and S. A. Louloudi, 'Joint-scalar transported PDF modeling of soot formation and oxidation', Proc. Combust. Inst., vol. 30, no. 1, pp. 775-783, 2005, doi: 10.1016/j.proci.2004.08.080.

[124] H. El-Asrag and S. Menon, 'Large eddy simulation of soot formation in a turbulent nonpremixed jet flame', Combust. Flame, vol. 156, no. 2, pp. 385-395, 2009, doi: 10.1016/j.combustflame.2008.09.003.

[125] D. Li, Z. Li, and Z. Gao, 'Quadrature-based moment methods for the population balance equation: An algorithm review', Chinese J. Chem. Eng., vol. 27, no. 3, pp. 483-500, 2019, doi: 10.1016/j.cjche.2018.11.028.

[126] J. C. Barrett and N. A. Webb, 'A comparison of some approximate methods for solving the aerosol general dynamic equation', J. Aerosol Sci., vol. 29, no. 1-2, pp. 31-39, 1998, doi: 10.1016/S0021-8502(97)00455-2.

[127] D. L. Marchisio, J. T. Pikturna, R. O. Fox, R. D. Vigil, and A. A. Barresi, 'Quadrature 
method of moments for population-balance equations', AIChE J., vol. 49, no. 5, pp. 12661276, 2003, doi: 10.1002/aic.690490517.

[128] C. Yuan and R. O. Fox, 'Conditional quadrature method of moments for kinetic equations', J. Comput. Phys., vol. 230, no. 22, pp. 8216-8246, 2011, doi: 10.1016/j.jcp.2011.07.020.

[129] W. Yuan, Y. Li, P. Dagaut, J. Yang, and F. Qi, 'Experimental and kinetic modeling study of styrene combustion', Combust. Flame, vol. 162, no. 5, pp. 1868-1883, 2015, doi: 10.1016/j.combustflame.2014.12.008.

[130] A. Wick, T. Nguyen, F. Laurent, R. O. Fox, and H. Pitsch, 'Modeling soot oxidation with the Extended Quadrature Method of Moments', Proc. Combust. Inst., vol. 36, no. 1, pp. 789-797, 2017, doi: 10.1016/j.proci.2016.08.004.

[131] S. Rigopoulos, 'Population balance modelling of polydispersed particles in reactive flows', Prog. Energy Combust. Sci., vol. 36, no. 4, pp. 412-443, 2010, doi: 10.1016/j.pecs.2009.12.001.

[132] R. Bleck, 'A Fast, Approximative Method for Integrating the Stochastic Coalescence Equation', vol. 75 , no. 27, pp. 5165-5171, 1970.

[133] M. J. Hounslow, R. L. Ryall, and V. R. Marshall, 'A discretized population balance for nucleation, growth, and aggregation', AIChE J., vol. 34, no. 11, pp. 1821-1832, 1988, doi: 10.1002/aic.690341108.

[134] S. Kumar and D. Ramkrishna, 'ON THE SOLUTION OF POPULATION BALANCE EQUATIONS BY DISCRETIZATION--I. A FIXED PIVOT TECHNIQUE', Chem. Eng. Sci., vol. 51, no. 8, pp. 1311-1322, 1996, doi: 10.1515/zna-1951-0407.

[135] S. Kumar and D. Ramkrishna, 'On the solution of population balance equations by discretization - II. A moving pivot technique', Chem. Eng. Sci., vol. 51, no. 8, pp. 13331342, 1996, doi: 10.1016/0009-2509(95)00355-X.

[136] S. H. Park and S. N. Rogak, 'A novel fixed-sectional model for the formation and growth of aerosol agglomerates', J. Aerosol Sci., vol. 35, no. 11, pp. 1385-1404, 2004, doi: 10.1016/j.jaerosci.2004.05.010.

[137] F. Gelbard and J. H. Seinfeld, 'Numerical solution of the dynamic equation for particulate systems', J. Comput. Phys., vol. 28, no. 3, pp. 357-375, 1978, doi: 10.1016/00219991(78)90058-X.

[138] M. Nicmanis and M. J. Hounslow, 'A finite element analysis of the steady state population balance equation for particulate systems : Aggregation and growth', Comput. Chem. Eng., 
vol. 20, no. SUPPL.1, 1996, doi: 10.1016/0098-1354(96)00054-3.

[139] S. Rigopoulos and A. G. Jones, 'Finite-element scheme for solution of the dynamic population balance equation', AIChE J., vol. 49, no. 5, pp. 1127-1139, 2003, doi: 10.1002/aic.690490507.

[140] D. Aubagnac-Karkar, A. El Bakali, and P. Desgroux, 'Soot particles inception and PAH condensation modelling applied in a soot model utilizing a sectional method', Combust. Flame, vol. 189, pp. 190-206, 2018, doi: 10.1016/j.combustflame.2017.10.027.

[141] P. Rodrigues, B. Franzelli, R. Vicquelin, O. Gicquel, and N. Darabiha, 'Unsteady dynamics of PAH and soot particles in laminar counterflow diffusion flames', Proc. Combust. Inst., vol. 36, no. 1, pp. 927-934, 2017, doi: 10.1016/j.proci.2016.07.047.

[142] S. Qamar and G. Warnecke, 'Solving population balance equations for two-component aggregation by a finite volume scheme', Chem. Eng. Sci., vol. 62, no. 3, pp. 679-693, 2007, doi: 10.1016/j.ces.2006.10.001.

[143] A. Liu and S. Rigopoulos, 'A conservative method for numerical solution of the population balance equation, and application to soot formation', Combust. Flame, vol. 205, pp. 506521, 2019, doi: 10.1016/j.combustflame.2019.04.019.

[144] S. Kumar and D. Ramkrishna, 'On the solution of population balance equations by discretization - III. Nucleation, growth and aggregation of particles', Chem. Eng. Sci., vol. 52, no. 24, pp. 4659-4679, 1997, doi: 10.1016/S0009-2509(97)00307-2.

[145] F. Sewerin and S. Rigopoulos, 'An explicit adaptive grid approach for the numerical solution of the population balance equation', Chem. Eng. Sci., vol. 168, pp. 250-270, 2017, doi: 10.1016/j.ces.2017.01.054.

[146] Y. Lin, K. Lee, and T. Matsoukas, 'Solution of the population balance equation using constant-number Monte Carlo', Chem. Eng. Sci., vol. 57, no. 12, pp. 2241-2252, 2002, doi: 10.1016/S0009-2509(02)00114-8.

[147] F. E. Kruis, A. Maisels, and H. Fissan, 'Direct simulation Monte Carlo method for particle coagulation and aggregation', AIChE J., vol. 46, no. 9, pp. 1735-1742, 2000, doi: 10.1002/aic.690460905.

[148] H. Zhao, F. E. Kruis, and C. Zheng, 'Reducing statistical noise and extending the size spectrum by applying weighted simulation particles in monte carlo simulation of coagulation', Aerosol Sci. Technol., vol. 43, no. 8, pp. 781-793, 2009, doi: 10.1080/02786820902939708.

[149] M. Goodson and M. Kraft, 'An efficienct stochastic algorithm for simulating nano-particle 
dynamics', J. Comput. Phys., vol. 183, no. 1, pp. 210-232, 2002, doi: 10.1006/jcph.2002.7192.

[150] R. I. A. Patterson, J. Singh, M. Balthasar, M. Kraft, and W. Wagner, 'Extending stochastic soot simulation to higher pressures', Combust. Flame, vol. 145, no. 3, pp. 638-642, 2006, doi: 10.1016/j.combustflame.2006.02.005.

[151] R. I. A. Patterson, W. Wagner, and M. Kraft, 'Stochastic weighted particle methods for population balance equations', J. Comput. Phys., vol. 230, no. 19, pp. 7456-7472, 2011, doi: $10.1016 /$ j.jcp.2011.06.011.

[152] M. Balthasar and M. Frenklach, 'Detailed kinetic modeling of soot aggregate formation in laminar premixed flames', Combust. Flame, vol. 140, no. 1-2, pp. 130-145, 2005, doi: 10.1016/j.combustflame.2004.11.004.

[153] A. Bouaniche, L. Vervisch, and P. Domingo, 'A hybrid stochastic/fixed-sectional method for solving the population balance equation', Chem. Eng. Sci., vol. 209, p. 115198, 2019, doi: 10.1016/j.ces.2019.115198.

[154] C. Pels Leusden and N. Peters, 'Experimental and numerical analysis of the influence of oxygen on soot formation in laminar counterflow flames of acetylene', Proc. Combust. Inst., vol. 28, no. 2, pp. 2619-2625, 2000, doi: 10.1016/s0082-0784(00)80680-3.

[155] H. Pitsch, 'FlameMaster, a C++ computer program for 0D combustion and 1D laminar flame calculations.' .

[156] G. Blanquart, P. Pepiot-Desjardins, and H. Pitsch, 'Chemical mechanism for high temperature combustion of engine relevant fuels with emphasis on soot precursors', Combust. Flame, vol. 156, no. 3, pp. 588-607, 2009, doi: 10.1016/j.combustflame.2008.12.007.

[157] S. T. Chong, V. Raman, M. E. Mueller, P. Selvaraj, and H. G. Im, 'Effect of soot model, moment method, and chemical kinetics on soot formation in a model aircraft combustor', Proc. Combust. Inst., vol. 37, no. 1, pp. 1065-1074, 2019, doi: 10.1016/j.proci.2018.06.093.

[158] K. P. Geigle, M. Köhler, W. O’Loughlin, and W. Meier, 'Investigation of soot formation in pressurized swirl flames by laser measurements of temperature, flame structures and soot concentrations', Proc. Combust. Inst., vol. 35, no. 3, pp. 3373-3380, 2015, doi: 10.1016/j.proci.2014.05.135.

[159] W. K. Metcalfe, S. M. Burke, S. S. Ahmed, and H. J. Curran, 'A hierarchical and comparative kinetic modeling study of C1 - C2 hydrocarbon and oxygenated fuels', Int. J. Chem. Kinet., vol. 45, no. 10, pp. 638-675, 2013, doi: 10.1002/kin.20802. 
[160] J. Zhang, C. R. Shaddix, and R. W. Schefer, 'Design of model-friendly turbulent nonpremixed jet burners for C 2+ hydrocarbon fuels', Rev. Sci. Instrum., vol. 82, no. 7, 2011, doi: 10.1063/1.3605491.

[161] 'International sooting flame (ISF) workshop website'. .

[162] M. Ihme and H. Pitsch, 'Modeling of radiation and nitric oxide formation in turbulent nonpremixed flames using a flamelet/progress variable formulation', Phys. Fluids, vol. 20, no. 5, pp. 1-21, 2008, doi: 10.1063/1.2911047.

[163] Y. Xuan and G. Blanquart, 'Effects of aromatic chemistry-turbulence interactions on soot formation in a turbulent non-premixed flame', Proc. Combust. Inst., vol. 35, no. 2, pp. 1911-1919, 2015, doi: 10.1016/j.proci.2014.06.138.

[164] A. D. Abid, N. Heinz, E. D. Tolmachoff, D. J. Phares, C. S. Campbell, and H. Wang, 'On evolution of particle size distribution functions of incipient soot in premixed ethyleneoxygen-argon flames', Combust. Flame, vol. 154, no. 4, pp. 775-788, 2008, doi: 10.1016/j.combustflame.2008.06.009. 